\title{
¿Unraveling Interactions between Asymmetric Tidal Turbulence, Residual Circulation, and Salinity Dynamics in Short, Periodically Weakly Stratified Estuaries
}

\author{
Xiaoyan Wei, ${ }^{\mathrm{a}}$ Henk M. Schuttelaars, ${ }^{\mathrm{b}}$ Megan E. Williams, ${ }^{\mathrm{c} a}$ Jennifer M. Brown, ${ }^{\mathrm{a}}$ \\ Peter D. Thorne, ${ }^{\mathrm{a}}$ AND LAurent O. Amoudry ${ }^{\mathrm{a}}$ \\ ${ }^{\text {a }}$ National Oceanography Centre, Liverpool, United Kingdom \\ ${ }^{\mathrm{b}}$ Delft Institute of Applied Mathematics, Delft University of Technology, Delft, Netherlands \\ ${ }^{\mathrm{c}}$ Departamento de Obras Civiles, Universidad Tecnica Federico Santa Maria, Valparaiso, Chile
}

(Manuscript received 30 June 2020, in final form 2 February 2021)

\begin{abstract}
Asymmetric tidal turbulence (ATT) strongly influences estuarine health and functioning. However, its impact on the three-dimensional estuarine dynamics and the feedback of water motion and salinity distribution on ATT remain poorly understood, especially for short estuaries (estuarine length « tidal wavelength). This study systematically investigates the abovementioned interactions in a short estuary for the first time, considering periodically weakly stratified conditions. This is done by developing a three-dimensional semi-analytical model (combining perturbation method with finite element method) that allows a dissection of the contributions of different processes to ATT, estuarine circulation, and salt transport. The generation of ATT is dominated by (i) strain-induced periodic stratification and (ii) asymmetric bottomshear-generated turbulence, and their contributions to ATT are different both in amplitude and phase. The magnitude of the residual circulation related to ATT and the eddy viscosity-shear covariance (ESCO) is about half of that of the gravitational circulation (GC) and shows a "reversed" pattern as compared to GC. ATT generated by strain-induced periodic stratification contributes to an ESCO circulation with a spatial structure similar to GC. This circulation reduces the longitudinal salinity gradients and thus weakens GC. Contrastingly, the ESCO circulation due to asymmetric bottom-sheargenerated turbulence shows patterns opposite to GC and acts to enhance GC. Concerning the salinity dynamics at steady state, GC and tidal pumping are equally important to salt import, whereas ESCO circulation yields a significant seaward salt transport. These findings highlight the importance of identifying the sources of ATT to understand its impact on estuarine circulation and salt distribution.
\end{abstract}

KEYWORDS: Baroclinic flows; Mass fluxes/transport; Turbulence; Salinity; Estuaries

\section{Introduction}

Vertical turbulent fluxes of momentum and salt are of fundamental importance to estuarine water motion and mass transport, hence strongly influencing the estuarine morphology, biology, and ecology. There fluxes are usually parameterized by means of a downgradient approach using a vertical eddy viscosity and diffusivity (based on Fick's law). Due to strong temporal variability of small-scale turbulence, the vertical eddy viscosity can change significantly in time (see, e.g., Peters 1997, 1999). Of particular interest in the present paper are the variations of vertical eddy viscosity and diffusivity at the dominant tidal frequency and their interactions with the water motion and salt transport. The dominant tidal component of these coefficients parameterizes variations of smallscale turbulence during the tidal cycle and is responsible for flood-ebb asymmetry in small-scale turbulence. Such asymmetries were first observed by Simpson et al. (1990) and will be called asymmetric tidal turbulence (ATT) hereafter.

Observations have highlighted the importance of ATT to estuarine circulation in many systems (Jay and Musiak 1994;

¿ Denotes content that is immediately available upon publication as open access.

Corresponding author: Xiaoyan Wei, xwei@noc.ac.uk
Stacey et al. 2001; Scully and Friedrichs 2003, 2007). Nevertheless, different flood-ebb asymmetries of turbulence were observed across different marine systems, implying the source of ATT and its impact on water motion and mass transport can also vary significantly. In the lower Hudson River estuary, Liverpool Bay, and the Dee estuary, for example, higher turbulence levels were observed during flood than ebb (Geyer et al. 2000; Simpson et al. 2002; Bolaños et al. 2013). In the Gironde estuary, higher turbulence levels were observed during ebb under neap conditions. However, during spring tides, turbulence was higher during flood (Ross et al. 2019).

These different ATT patterns are associated with many processes. Higher turbulence levels during the flood tide are usually attributed to strain-induced periodic stratification (SIPS; Simpson et al. 1990, 2002, 2005; Stacey and Ralston 2005; Cheng et al. 2010), flood-dominant bottom-sheargenerated turbulence (BGT; see, e.g., West and Shiono 1988; Li and Zhong 2009), and convective instabilities (Rippeth et al. 2001; Prandle 2004; Stacey and Ralston 2005). In contrast, stronger turbulence during ebb is attributed to shear instability (Geyer 1995), ebb-dominant BGT (Simons et al. 2010; Ross et al. 2019), and lateral processes (Scully and Geyer 2012;

This article is licensed under a Creative Commons Attribution 4.0 license (http://creativecommons.org/ licenses/by/4.0/). 
Basdurak et al. 2017). In addition, the tidally varying water depth (TWD) effectively influences the development of turbulence in shallow waters by limiting the maximum eddy size (Uijttewaal and Booij 2000), and may also result in a nonnegligible contribution to the ATT in shallow, meso/macrotidal estuaries.

The contribution of ATT to estuarine circulation originates from the eddy viscosity-shear covariance (ESCO), hence will be called ESCO circulation, as proposed by Dijkstra et al. (2017). Many process-based models have been employed to understand and quantify the contribution of this circulation. Stacey et al. (2008) found the ESCO circulation can be more significant than gravitational circulation (GC) under moderate water depths and stratification, and the phasing of ATT relative to the shear determines whether the ESCO circulation has a similar or opposite vertical structure to GC. These results were confirmed by Cheng et al. (2010) with a width-averaged analytical model as well as a three-dimensional numerical model (considering weakly stratified narrow estuaries with a constant water depth). The relative importance of ESCO circulation to estuarine circulation was first quantified by Burchard and Hetland (2010). Using a one-dimensional water column model coupled to a turbulence closure model, they found that in periodically stratified estuaries ESCO circulation is about twice as important as GC, and the significance of the ESCO circulation decreases with increasing down-estuary wind straining and residual runoff. They also found the ESCO circulation has a vertical structure similar to GC but the structure is "reversed" when considering strong down-estuary wind straining. Extending Burchard and Hetland's (2010) model to a (two-dimensional) crosssectional model, Burchard et al. (2011) found strong dependence of the relative importance of ESCO circulation on the Simpson number $S_{i}$ (ratio of horizontal buoyancy gradient to bottom frictional velocity scale). For large $S_{i}$, GC is stronger than ESCO circulation; for small $S_{i}$, ESCO circulation dominates the estuarine circulation. Following the same framework, Burchard and Schuttelaars (2012) found that the lateral advection of longitudinal momentum significantly influences ESCO circulation in estuaries with a parabolic cross section. Their results highlight the importance of lateral processes to the along-channel estuarine circulation, as found by Lerczak and Geyer (2004) using a three-dimensional (3D) numerical model. Using the same approach of Burchard and Hetland (2010), Dijkstra et al. (2017) found that ESCO directly influences estuarine circulation through not only the covariance between tidal shear and tidal variations of vertical eddy viscosity, but also the covariance between shear and eddy viscosity at twice the dominant tidal frequency. Moreover, the tidally varying eddy viscosity can interact with GC and indirectly contribute to ESCO circulation. By employing a numerical width-averaged model, they further demonstrated significant variations of the relative importance of GC, and the direct and indirect ESCO circulation components along the Scheldt estuary.

However, as longitudinal salinity gradients need to be prescribed in water-column and cross-sectional models and lateral processes are neglected in width-averaged models, the 3D interactions between ATT and salinity gradients remain poorly understood, as well as their influence on the gravitational and ESCO circulation. Moreover, most three-dimensional and width-averaged modeling studies have focused on long estuaries, in which the estuarine length and tidal wavelength are within the same order of magnitude. The importance of asymmetric tidal turbulence to estuarine circulation and salt transport in short estuaries (estuarine length $\ll$ tidal wavelength) is yet to be evaluated.

One major difference between short estuaries and long estuaries lies in the tidal propagation. The tide behaves mostly as a standing wave (with some features of a progressive wave) in short estuaries and a progressive wave in long estuaries (Dronkers 1986). This has direct consequences for estuarine circulation and salt transport. For example, the residual circulation due to tidal return flow (that compensates the Stokes drift) is close to zero in very short tidal basins as a result of weak correlations between the tidal surface elevation and surface velocities. In long estuaries, however, tidal return flow can generate strong seaward residual flow (Dronkers 1986). Moreover, the residual salt flux due to tidal advection of salinity (i.e., tidal pumping) dominates the landward salt transport in long estuaries (Wei et al. 2017), but is close to zero in very short estuaries due to weak correlations between the tidal velocity and salinity (Schettini et al. 2017). Another important distinction is linked to the along-channel salinity gradients, which are usually large in short estuaries (such as the Tamar, Tees, and Wyre estuaries in the United Kingdom) compared to long estuaries (Lewis and Uncles 2003) and can lead to stronger gravitational circulation in shorter estuaries (with large $S_{i}$ number). This implies that our knowledge of dominant processes for estuarine circulation and salt transport established for long estuaries may not hold for short estuaries.

Hence, there are three main goals in this study: 1) to develop a semi-analytical model that allows for a threedimensional investigation of the mutually interacting water motion, salinity distribution, and small-scale turbulence, focusing on ATT in tidally dominated, periodically weakly stratified estuaries; 2) to systematically quantify the individual contributions of asymmetric bottom-shear-generated turbulence, strain-induced periodic stratification, and water depth variations to ATT, estuarine circulation, and salt transport in a short estuary; and 3) to investigate the feedback of water motion and salt transport on ATT. The solution method employed in this study also allows for a systematic interpretation framework for the complex variations of turbulence commonly observed in numerical models and field measurements.

This paper is organized as follows: the research method is described in section 2 ; in section 3 , the contributions of straininduced turbulence, asymmetric bottom-shear-generated turbulence, and water depth variations to the asymmetric tidal turbulence, and the mutual interactions between asymmetric tidal turbulence, currents, and salinity distribution are investigated; section 4 briefly discusses the model capabilities and limitations; and conclusions are presented in section 5 . 


\section{Research method}

\section{a. Model description}

The estuarine dynamics considered here is strongly nonlinear due to interactions between turbulence, shear, and stratification: small-scale turbulence can strongly influence the water motion and salinity distribution; meanwhile, the shear acts to generate turbulence, which is inhibited by stable stratification and promoted by unstable stratification. To resolve the estuarine dynamics in a way that allows for a systematic decomposition of the abovementioned interactions, the 3D semi-analytical model of Wei et al. (2017) is extended in this study. In Wei et al. (2017), the nonlinearly coupled water motion and salt dynamics are resolved, decomposing temporal variations into a semidiurnal $\left(\mathrm{M}_{2}\right)$ tidal constituent and a residual $\left(\mathrm{M}_{0}\right)$ signal both for the water motion and salinity. In this model, a time-independent vertical eddy viscosity $A_{v}$ and diffusivity $K_{v}$ are prescribed, thus neglecting the influence of temporal variations of $A_{v}$ and $K_{v}$ on the hydro- and salt dynamics. To dynamically include this temporal variability which is directly linked to the asymmetric tidal turbulence (ATT), three main extensions are made. First, $A_{v}$ and $K_{v}$ are dynamically coupled to the water motion and stratification, resulting in a tidally varying $A_{v}$ and $K_{v}$. Second, the contribution of this temporal variability of $A_{v}$ and $K_{v}$ to estuarine circulation (ESCO) and salt transport are taken into account. Third, the quarter-diurnal $\left(\mathbf{M}_{4}\right)$ tidal motion [see Eq. (9)] is resolved because it plays a nonnegligible role in the generation of ATT and is partly originated from the covariance of eddy viscosity and shear at the semidiurnal frequency.

\section{1) EXTENDING THE 3D SEMI-ANALYTICAL MODEL}

\section{(i) Governing equations and boundary conditions}

The model considers an idealized, periodically weakly stratified estuary with a simplified bathymetry and geometry (see Fig. 1). The water motion is described by the threedimensional shallow water equations under the Boussinesq approximation and the hydrostatic assumption, neglecting effects of horizontal eddy viscosity. The hydrodynamic equations read

$$
\begin{aligned}
& \frac{\partial u}{\partial x}+\frac{\partial v}{\partial y}+\frac{\partial w}{\partial z}=0 \\
& \frac{\partial u}{\partial t}+\nabla \cdot(\mathbf{U} u)=f v-g \frac{\partial \eta}{\partial x}-\frac{g}{\rho_{c}} \int_{z}^{\eta} \frac{\partial \rho}{\partial x} d z+\frac{\partial}{\partial z}\left(A_{v} \frac{\partial u}{\partial z}\right) \\
& \frac{\partial v}{\partial t}+\nabla \cdot(\mathbf{U} v)=-f u-g \frac{\partial \eta}{\partial y}-\frac{g}{\rho_{c}} \int_{z}^{\eta} \frac{\partial \rho}{\partial y} d z+\frac{\partial}{\partial z}\left(A_{v} \frac{\partial v}{\partial z}\right)
\end{aligned}
$$

and the salinity equation is given by

$$
\frac{\partial S}{\partial t}+\nabla \cdot(\mathbf{U S})=\frac{\partial}{\partial x}\left(K_{h} \frac{\partial S}{\partial x}\right)+\frac{\partial}{\partial y}\left(K_{h} \frac{\partial S}{\partial y}\right)+\frac{\partial}{\partial z}\left(K_{v} \frac{\partial S}{\partial z}\right) .
$$

Here $t$ denotes time, $\eta$ is the free surface elevation, and $\mathbf{U}=(u, v, w)$ is the velocity vector, with $u, v$, and $w$ the velocity components in $x, y$, and $z$ directions, respectively. The acceleration due to gravity is denoted by $g$. The Coriolis

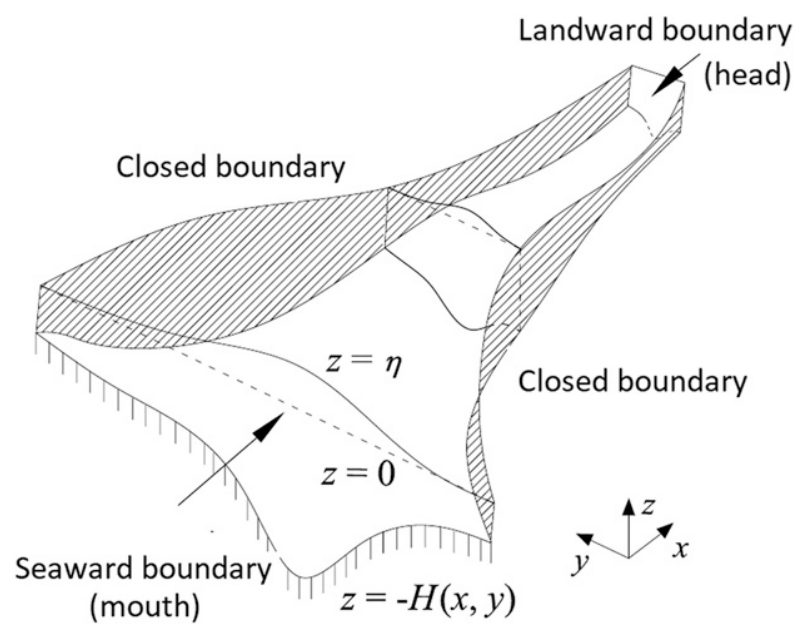

FIG. 1. Sketch of the idealized estuary. Here $x$ and $y$ are the horizontal coordinates, and $z$ is the vertical coordinate, positive in the upward direction. The free surface elevation and the bottom are located at $z=\eta$ and $z=-H(x, y)$, respectively. The undisturbed water level is at $z=0$. Source: Wei et al. (2017).

parameter is given by $f$. The estuarine water density is represented by $\rho$, which is assumed to depend only on salinity $S$ as $\rho=\rho_{\mathrm{c}}\left(1+\beta_{s} S\right)$, with $\beta_{s}=7.6 \times 10^{-4} \mathrm{psu}^{-1}$ and a constant background density $\rho_{c}=1000 \mathrm{~kg} \mathrm{~m}^{-3}$. The term $K_{h}$ is the horizontal eddy diffusivity.

At the seaward boundary, the water motion is forced by a prescribed, laterally homogeneous sea surface elevation that consists of a semidiurnal tidal constituent, $\mathrm{M}_{2}$, its first overtide, $\mathrm{M}_{4}$, and a residual sea surface elevation, $\mathrm{M}_{0}$, with the widthaveraged residual sea surface amplitude equal to zero. A freshwater discharge $Q$ is prescribed at the landward boundary, $x=L$, where a weir is located. The closed boundaries are impermeable, and the normal component of the depthintegrated water flux is zero at these boundaries. By requiring depth-averaged water flux to vanish at the closed boundaries (instead of a no-slip condition), the dynamics within regions close to these boundaries, where horizontal stresses play an important role in the momentum balance, is not resolved in this model. At the free surface, kinematic and no stress boundary conditions are prescribed. The bottom is impermeable and a partial slip condition is applied, assuming linearized bottom shear stress as first proposed by Lorentz (1926):

$$
A_{v} \partial(u, v) / \partial z=s(u, v)
$$

with $s$ the partial slip parameter. The partial slip parameter is chosen such that the energy dissipation per tidal cycle equals the dissipation obtained with a quadratic bottom friction. The partial slip bottom boundary condition is applied at the top of the logarithmic boundary layer, as described in Zitman and Schuttelaars (2012). The linearized bottom friction assumption is essential to directly solving the water motion at each tidal frequency and dissecting the contributions of different processes to residual circulation and salt transport in this model. To close the salinity problem, a spatially uniform 
tidally averaged salinity $S_{m}$ is prescribed at the mouth. The salt flux through the free surface and bottom, and the depthintegrated tidally averaged salt transport normal to the closed boundaries are equal to zero.

\section{(ii) Semi-analytical approach}

A semi-analytical approach is taken to solve the water motion, salinity, and vertical eddy viscosity and diffusivity, combining a perturbation method with a finite element method and assuming all these variables to consist of different tidal constituents. As the first step of the perturbation method, the system of equations is reduced to an ordered system of equations by making the equations dimensionless and comparing each term with a small parameter $\varepsilon \ll 1$, the ratio of the semidiurnal tidal surface amplitude to the undisturbed water depth at the mouth. This results in a system of equations at each order of $\varepsilon$, which describes the water motion and salinity at specific tidal frequencies (appendixes A-D). The equations at each order can be solved separately. When using a vertically uniform tidally averaged vertical eddy viscosity and diffusivity, the perturbation method allows the vertical shape functions of all physical variables at each tidal frequency to be obtained analytically from the top of the logarithmic layer to the undisturbed water level. Then, the horizontal distribution of all physical variables is solved using a finite element method.

The decomposition of the water motion and salinity in tidal constituents is included below for clarity. As given by Wei et al. (2017, 2018), for tidally dominated estuaries, the water motion is composed of a leading-order $\mathrm{M}_{2}$ tidal constituent, and a first-order $\mathrm{M}_{0}$ and $\mathrm{M}_{4}$ component [neglecting terms of $O\left(\varepsilon^{2}\right)$ and higher],

$$
\begin{gathered}
\eta=\underbrace{\eta_{\mathrm{M}_{2}}}_{O(1)}+\underbrace{\eta_{\mathrm{M}_{0}}+\eta_{\mathrm{M}_{4}}}_{O(\varepsilon)}, \\
\mathbf{U}=\underbrace{\mathbf{U}_{\mathrm{M}_{2}}}_{O(1)}+\underbrace{\mathbf{U}_{\mathrm{M}_{0}}+\mathbf{U}_{\mathrm{M}_{4}}}_{O(\varepsilon)} .
\end{gathered}
$$

Here, $\eta_{\mathrm{M}_{2}}$ and $\mathbf{U}_{\mathrm{M}_{2}}$ are respectively the leading-order tidal elevation and velocity at the $\mathrm{M}_{2}$ tidal frequency, $\eta_{\mathrm{M}_{4}}$ and $\mathbf{U}_{\mathrm{M}_{4}}$ are the first-order tidal elevation and velocity at the $\mathbf{M}_{4}$ tidal frequency, and $\eta_{\mathrm{M}_{0}}$ and $\mathbf{U}_{\mathrm{M}_{0}}$ are the subtidal elevation and flow velocity. The residual circulation can be separated into various contributions:

$$
\mathbf{U}_{\mathrm{M}_{0}}=\mathbf{U}_{\mathrm{M}_{0}}^{\mathrm{RD}}+\mathbf{U}_{\mathrm{M}_{0}}^{\mathrm{TRFSD}}+\mathbf{U}_{\mathrm{M}_{0}}^{\mathrm{NS}}+\mathbf{U}_{\mathrm{M}_{0}}^{\mathrm{AC}}+\mathbf{U}_{\mathrm{M}_{0}}^{\mathrm{GC}}+\mathbf{U}_{\mathrm{M}_{0}}^{\mathrm{ESCO}} .
$$

These include the subtidal flow induced by river discharge $\left(\mathbf{U}_{\mathrm{M}_{0}}^{\mathrm{RD}}\right)$, tidal return flow that compensates the Stokes drift $\left(\mathbf{U}_{\mathrm{M}_{0}}^{\mathrm{TRFS}}\right)$, no-shear condition at the free surface $\left(\mathbf{U}_{\mathrm{M}_{0}}^{\mathrm{NS}}\right)$, tidal rectification of the $\mathrm{M}_{2}$ tide (i.e., advection, $\mathbf{U}_{\mathrm{M}_{0}}^{\mathrm{AC}}$ ), gravitational circulation $\left(\mathbf{U}_{\mathrm{M}_{0}}^{\mathrm{GC}}\right)$, and eddy viscosity-shear covariance $\left(\mathbf{U}_{\mathrm{M}_{0}}^{\mathrm{ESCO}}\right)$. Similarly, the $\mathrm{M}_{4}$ tidal flow can be decomposed into contributions by tidal return flow $\left(\mathbf{U}_{\mathrm{M}_{4}}^{\mathrm{TRFSD}}\right)$, no-shear surface condition $\left(\mathbf{U}_{\mathrm{M}_{4}}^{\mathrm{NS}}\right)$, advection $\left(\mathbf{U}_{\mathrm{M}_{4}}^{\mathrm{AC}}\right)$, eddy viscosity-shear covariance $\left(\mathbf{U}_{\mathrm{M}_{4}}^{\mathrm{ESCO}}\right)$, and the externally forced $\mathrm{M}_{4}$ tide $\left(\mathbf{U}_{\mathrm{M}_{4}}^{\mathrm{EF}}\right)$,

$$
\mathbf{U}_{\mathrm{M}_{4}}=\mathbf{U}_{\mathrm{M}_{4}}^{\mathrm{TRFSD}}+\mathbf{U}_{\mathrm{M}_{4}}^{\mathrm{NS}}+\mathbf{U}_{\mathrm{M}_{4}}^{\mathrm{AC}}+\mathbf{U}_{\mathrm{M}_{4}}^{\mathrm{ESCO}}+\mathbf{U}_{\mathrm{M}_{4}}^{\mathrm{EF}} .
$$

Under weakly stratified conditions, salinity primarily consists of a leading-order $\mathrm{M}_{0}$ component, $S_{\mathrm{M}_{0}}$, that is vertically homogeneous and time independent, and a first-order $\mathrm{M}_{2}$ component, $S_{\mathrm{M}_{2}}$, with a vertical structure,

$$
S=\underbrace{S_{\mathrm{M}_{0}}(x, y)}_{O(1)}+\underbrace{S_{\mathrm{M}_{2}}(t, x, y, z)}_{O(\varepsilon)} .
$$

Turbulence in estuaries dominated by a semidiurnal tide consists of components at various tidal frequencies (e.g., $\mathrm{M}_{0}$, $\mathrm{M}_{2}, \mathrm{M}_{4}, \mathrm{M}_{6}$ ) due to generation of overtides. Focusing on the ATT, this study considers only the residual component of the vertical eddy viscosity and diffusivity (i.e., $A_{v_{\mathrm{M}_{0}}}, K_{v_{\mathrm{M}_{0}}}$ ), that are time independent, and the semidiurnal component (i.e., $A_{v_{\mathrm{M}_{2}}}$, $K_{v_{\mathrm{M}_{2}}}$ ), that depends on the instantaneous water motion and stratification [see section 2a(3)]. In this study, $A_{v_{\mathrm{M}_{0}}}$ and $K_{v_{\mathrm{M}_{0}}}$ are assumed to be depth independent, and a unity PrandtlSchmidt number is considered for simplicity. Consequences of making these assumptions are discussed in section 4 . Following Cheng et al. (2010), the semidiurnal component is assumed to be one order of magnitude smaller than the residual component,

$$
A_{v}=K_{v}=\underbrace{A_{v_{\mathrm{M}_{0}}}(x, y)}_{O(1)}+\underbrace{A_{v_{\mathrm{M}_{2}}}(t, x, y, z)}_{O(\varepsilon)} .
$$

Note that the temporal correlations between $A_{v_{\mathrm{M}_{2}}}$ and the semidiurnal tidal shear contribute to both the residual circulation and quarter-diurnal tide, i.e., $\mathbf{U}_{\mathrm{M}_{0}}^{\mathrm{ESCO}}$ and $\mathbf{U}_{\mathrm{M}_{4}}^{\mathrm{ESCO}}$ [see section $2 \mathrm{a}(2)$ ]. The residual ESCO circulation yields an important contribution to redistributing salinity. However, since $S_{\mathrm{M}_{2}}$ is an order of magnitude lower than $S_{\mathrm{M}_{0}}$ in periodically weakly stratified estuaries (see, e.g., Bolaños et al. 2013), the temporal correlations between $K_{v_{\mathrm{M}_{2}}}$ (equal to $A_{v_{\mathrm{M}_{2}}}$ ) and vertical gradient of $S_{\mathrm{M}_{2}}$ have no impact on the residual salinity distribution [see Eq. (C1) in appendix C].

\section{2) The ESCO FLOW}

The full system of equations for the first-order water motion is linear due to the linearized bottom friction (details in appendix B). Hence, the ESCO flow can be obtained by considering only the forcings associated with the temporal correlations between $A_{v_{\mathrm{M}_{2}}}$ and the $\mathrm{M}_{2}$ vertical shear:

$$
\begin{gathered}
\frac{\partial u_{\mathrm{M}_{j}}^{\mathrm{ESCO}}}{\partial x}+\frac{\partial v_{\mathrm{M}_{j}}^{\mathrm{ESCO}}}{\partial y}+\frac{\partial w_{\mathrm{M}_{j}}^{\mathrm{ESCO}}}{\partial z}=0, \\
g \frac{\partial \eta_{\mathrm{M}_{j}}^{\mathrm{ESCO}}}{\partial x}=f v_{\mathrm{M}_{j}}^{\mathrm{ESCO}}+\frac{\partial}{\partial z}\left(A_{v_{\mathrm{M}_{0}}} \frac{\partial u_{\mathrm{M}_{j}}^{\mathrm{ESCO}}}{\partial z}+A_{v_{\mathrm{M}_{2}}} \frac{\partial u_{\mathrm{M}_{2}}}{\partial z}\right), \\
g \frac{\partial \eta_{\mathrm{M}_{j}}^{\mathrm{ESCO}}}{\partial y}=-f u_{\mathrm{M}_{j}}^{\mathrm{ESCO}}+\frac{\partial}{\partial z}\left(A_{v_{\mathrm{M}_{0}}} \frac{\partial v_{\mathrm{M}_{j}}^{\mathrm{ESCO}}}{\partial z}+A_{v_{\mathrm{M}_{2}} \frac{\partial v_{\mathrm{M}_{2}}}{\partial z}}\right) .
\end{gathered}
$$

Here $\eta_{\mathrm{M}_{j}}^{E S C O}$ is the ESCO-induced surface elevation, with $j=$ 0,4 . For $j=0$, overbars indicate tidal average. For $j=4$, overbars indicate that only the $\mathrm{M}_{4}$ tidal component is selected.

At the mouth, the width-averaged $\eta_{\mathrm{M}_{0}}^{E S C O}$ and $\eta_{\mathrm{M}_{4}}^{E S C O}$ are required to be zero. At the closed and landward boundaries, the 
normal component of the depth-integrated ESCO induced water flux is required to vanish,

$$
\left(\int_{-H}^{0} u_{\mathrm{M}_{j}}^{E S C O} d z, \int_{-H}^{0} v_{\mathrm{M}_{j}}^{\mathrm{ESCO}} d z\right) \cdot \mathbf{n}_{h}=0 .
$$

Here $\mathbf{n}_{h}$ is the unit horizontal vector normal to the boundaries. At the undisturbed water level $z=0$, the shear stress is equal to zero,

$$
A_{v_{\mathrm{M}_{0}}}\left(\frac{\partial u_{\mathrm{M}_{j}}^{\mathrm{ESCO}}}{\partial z}, \frac{\partial v_{\mathrm{M}_{j}}^{\mathrm{ESCO}}}{\partial z}\right)=(0,0) .
$$

At $z=-H$, a linearized partial slip boundary condition is applied,

$$
\begin{aligned}
A_{v_{\mathrm{M}_{0}}}\left(\frac{\partial u_{\mathrm{M}_{j}}^{\mathrm{ESCO}}}{\partial z}, \frac{\partial v_{\mathrm{M}_{j}}^{\mathrm{ESCO}}}{\partial z}\right)= & s\left(u_{\mathrm{M}_{j}}^{\mathrm{ESCO}}, v_{\mathrm{M}_{j}}^{\mathrm{ESCO}}\right) \\
& -\left(A_{v_{\mathrm{M}_{2}}} \frac{\partial u_{\mathrm{M}_{2}}}{\partial z}, A_{v_{\mathrm{M}_{2}}} \frac{\partial v_{\mathrm{M}_{2}}}{\partial z}\right) .
\end{aligned}
$$

With known information on the $\mathrm{M}_{2}$ tidal motion, $A_{v_{\mathrm{M}_{0}}}$ and $A_{v_{\mathrm{M}_{2}}}$, the system of Eqs. (12)-(17) can be solved by introducing rotating flow variables (Kumar et al. 2017).

\section{3) PARAMETERIZING SMALL-SCALE TURBULENCE}

To allow for a dynamic dependence of turbulence on the flow and stratification in the extended model, the vertical eddy viscosity $A_{v}$ and diffusivity $K_{v}$ are derived for each tidal frequency using an empirical formula. Basdurak et al. (2013) proposed a vertical eddy viscosity formula including dependencies on both the depth-averaged velocity and the gradient Richardson number $R_{i}$,

$$
R_{i}=-\frac{g}{\rho_{c}} \frac{\frac{\partial \rho}{\partial z}}{\left(\frac{\partial u}{\partial z}\right)^{2}+\left(\frac{\partial v}{\partial z}\right)^{2}}
$$

defined as the ratio of the vertical buoyancy gradient to the vertical shear squared. Their parameterization reads

$$
A_{v}=c_{0} H \sqrt{\bar{u}^{2}+\bar{v}^{2}}\left(1+5 R_{i}\right)^{-2} \beta_{z}+\hat{A}_{v}
$$

with $c_{0}=2.5 \times 10^{-3}, \hat{A}_{v}=10^{-4} \mathrm{~m}^{2} \mathrm{~s}^{-1}$, following Davies et al. (1997) and Pacanowski and Philander (1981), respectively. Here $H$ is the undisturbed water depth, and $\bar{u}$ and $\bar{v}$ are the vertically averaged horizontal velocity components; $\beta_{z}$ is a function of depth, which is equal to unity above $z=-0.1 H$ (following Davies et al. 1997), and is smaller than unity below $-0.1 H$. This formula considers not only the fact that large gradient Richardson numbers dampen turbulence, but also that turbulent flow generates mixing. By fitting $\hat{A}_{v}$ to their microstructure profiler data, Basdurak et al. (2013) found Eq. (19) reproduces quantitatively the patterns of the observed vertical eddy viscosity at a transect of the lower James River estuary. Using a separate set of in situ microstructure data, Basdurak et al. (2017) confirmed this parameterization compares well with their microstructure data derived $A_{v}$ in the James River estuary under weakly stratified conditions except over the northern shoal. This implies that the dominant influencing factors for $A_{v}$, i.e., current and stratification, are reasonably well represented by this formula for weakly stratified conditions. Therefore, this formula is considered appropriate for parameterizing the contributions of these two factors to $A_{v}$ in the idealized periodically stratified estuary focused upon in the present study.

The lower James River estuary has a tidal range of $\sim 0.9 \mathrm{~m}$ during spring tides and $0.4 \mathrm{~m}$ during neap, so tidal elevation is negligible compared to the water depth. In shallow meso/macrotidal estuaries, however, the water depth varies significantly within the tidal cycle. This can have a nonnegligible influence on the eddy development and turbulence generation throughout the water column (Uijttewaal and Booij 2000), an effect not taken into account in Eq. (19). To account for this, the tidal elevation is included in the parameterization for this study,

$$
A_{v}=c_{0}(\eta+H) \sqrt{\bar{u}^{2}+\bar{v}^{2}}\left(1+5 R_{i}^{*}\right)^{-2} \beta_{z}+\hat{A}_{v} .
$$

Here, $\beta_{z}$ is taken to be unity at all depths for simplicity. This simplification does not account for the tendency that the size of turbulent eddies decreases with distance toward the bottom within the logarithmic boundary layer (see, e.g., Townsend 1961), i.e., Prandtl's mixing length concept. This is reasonable because the logarithmic boundary layer is not resolved in the idealized model due to the partial slip condition being applied at a distance above the bed as described before. More importantly, including the vertical variations of $A_{v}$ near the bottom does not qualitatively impact the tidal or residual flow patterns (Zitman and Schuttelaars 2012), even though quantitative changes may be found such as an overestimation of $A_{v}$ and velocities near the bed (Davies et al. 1997).

The gradient Richardson number $R_{i}^{*}$ is defined as

$$
R_{i}^{*}=\max \left[R_{i}, R_{i_{\min }}\right]
$$

in which a minimum value of $R_{i}^{*}, R_{i_{\min }}$, is introduced. To avoid infinite values of vertical eddy viscosity and diffusivity, $R_{i_{\text {min }}}$ has to be larger than -0.2 . By allowing negative values of $R_{i}^{*}$ (for $R_{i_{\min }}<0$ ), the enhanced turbulence due to convection (in the presence of unstable stratification) is represented in Eq. (20). The vertical eddy viscosity/diffusivity at each frequency (e.g., $\mathrm{M}_{0}, \mathrm{M}_{2}$ ) can then be derived by extracting the tidally averaged and semidiurnal components of $A_{v}$ (ignoring the other frequencies) using a Fourier transform $(\mathscr{F})$ :

$$
\begin{aligned}
& A_{v \mathrm{M}_{0}}=\mathscr{F}^{\mathrm{M}_{0}}\left\{A_{v}\right\}, \\
& A_{v \mathrm{M}_{2}}=\mathscr{F}^{\mathrm{M}_{2}}\left\{A_{v}\right\} .
\end{aligned}
$$

Hence, the $\mathrm{M}_{2}$ vertical eddy viscosity can be also written as

$$
A_{v_{\mathrm{M}_{2}}}=\mathfrak{R}\left\{\hat{A}_{v_{\mathrm{M}_{2}}} \exp \left[i\left(\sigma_{\mathrm{M}_{2}} t-\phi_{\hat{A}_{\mathrm{M}_{2}}}\right)\right]\right\},
$$




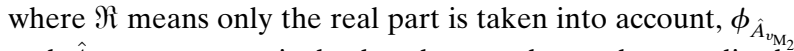
and $\hat{A}_{v_{\mathrm{M}_{2}}}$ are respectively the phase and complex amplitude of $A_{v_{\mathrm{M}_{2}}}$, and $\sigma_{\mathrm{M}_{2}}$ is the $\mathrm{M}_{2}$ tidal frequency. Higher-frequency terms are neglected in the present study to focus on the ATT associated with the flood-ebb turbulence asymmetries. As the residual and quarter-diurnal tidal currents are usually one order of magnitude smaller than the semidiurnal currents, and $R_{i}^{*}$ is small in weakly stratified estuaries, the influence of residual circulation, quarter-diurnal tidal currents, and $R_{i}^{*}$ on $A_{v_{\mathrm{M}_{0}}}$ is also neglected for simplicity. This results in a reduced form of (22) that depends only on the depth-averaged semidiurnal tidal velocities and the undisturbed water depth:

$$
A_{v_{\mathrm{M}_{0}}} \approx \mathscr{T}^{\mathrm{M}_{0}}\left\{c_{0} H \sqrt{\bar{u}_{\mathrm{M}_{2}}^{2}+\bar{v}_{\mathrm{M}_{2}}^{2}}+\hat{A}_{v}\right\}
$$

\section{4) Dissecting the ASYMMeTric tidal turbulenCE}

The influence of bottom-shear-generated turbulence (BGT), strain-induced periodic stratification (SIPS), and tidal variations of water depth (TWD) on the asymmetric tidal turbulence, which are all included in Eq. (20), can be evaluated individually by dissecting $A_{v_{\mathrm{M}_{2}}}$ in three terms:

$$
A_{v_{\mathrm{M}_{2}}}=A_{v_{\mathrm{M}_{2}}}^{\mathrm{BGT}}+A_{v_{\mathrm{M}_{2}}}^{\mathrm{SIPS}}+A_{v_{\mathrm{M}_{2}}}^{\mathrm{TWD}}
$$

with

$$
\begin{aligned}
& A_{v_{\mathrm{M}_{2}}}^{\mathrm{BGT}}=\mathscr{F}^{\mathrm{M}_{2}}\left\{c_{0} H \sqrt{\bar{u}^{2}+\bar{v}^{2}}\right\}, \\
& A_{v_{\mathrm{M}_{2}}}^{\mathrm{SIPS}}=\mathscr{F}^{\mathrm{M}_{2}}\left\{c_{0} H \sqrt{\bar{u}^{2}+\bar{v}^{2}}\left[\left(1+5 R_{i}^{*}\right)^{-2}-1\right]\right\}, \\
& A_{v_{\mathrm{M}_{2}}}^{\mathrm{TWD}}=\mathscr{F}^{\mathrm{M}_{2}}\left\{c_{0} \eta \sqrt{\bar{u}^{2}+\bar{v}^{2}}\left(1+5 R_{i}^{*}\right)^{-2}\right\} .
\end{aligned}
$$

Here, $A_{v_{\mathrm{M}_{2}}}^{\mathrm{BGT}}$ is derived by considering only the effect of BGT; $A_{v_{\mathrm{M}_{2}}}^{\mathrm{SIPS}}$ is derived by taking the difference between $A_{v_{\mathrm{M}_{2}}}$ generated by both SIPS and BGT, and that generated by BGT only; finally $A_{v_{\mathrm{M}_{2}}}^{\mathrm{TWD}}$ is obtained by subtracting $A_{v_{\mathrm{M}_{2}}}^{\text {SIPS }}$ and $A_{v_{\mathrm{M}_{2}}}^{\mathrm{BGT}}$ from Eq. (23).

\section{5) ITERATIVE METHOD}

An iterative approach is used to solve the coupled system of equations. For a given distribution of $A_{v_{\mathrm{M}_{0}}}$, the $\mathrm{M}_{2}$ tidal water motion can be calculated following the same procedure of Kumar et al. (2016). However, due to the dependence of $A_{v_{\mathrm{M}_{0}}}$ on the $\mathrm{M}_{2}$ flow itself [see Eq. (25)], the leading-order $\mathrm{M}_{2}$ water motion needs to be calculated iteratively together with $A_{v_{\mathrm{M}_{0}}}$. As the first step, a spatially uniform $A_{v_{\mathrm{M}_{0}}}$ is used to calculate the semidiurnal, $\mathrm{M}_{2}$ tide. Then, the information on the $\mathrm{M}_{2}$ tide is used in Eq. (25) to derive a new $A_{v_{\mathrm{M}_{0}}}$. In the next iteration step, the updated $A_{v_{\mathrm{M}_{0}}}$ yields a new solution for the $\mathrm{M}_{2}$ water motion, which is then fed back into Eq. (25) to derive a new $A_{v_{\mathrm{M}_{0}}}$. The final solution of $A_{v_{\mathrm{M}_{0}}}$ and the $\mathrm{M}_{2}$ water motion are obtained when the domain-averaged relative difference between the old $A_{v_{\mathrm{M}_{0}}}$ and the updated $A_{v_{\mathrm{M}_{0}}}$ is smaller than $0.1 \%$. After solving the $\mathrm{M}_{2}$ tide and $A_{v_{\mathrm{M}_{0}}}$, the barotropic residual and quarter-diurnal tidal flow due to river discharge, advection, stress-free surface condition and tidal return flow, which are independent of salinity and $A_{v_{\mathrm{M}_{2}}}$, can be solved (Kumar et al. 2017).

The gravitational circulation, GC, is coupled with salinity, and needs to be solved together with salinity (Wei et al. 2017). The ESCO circulation is strongly determined by $A_{v_{\mathrm{M}_{2}}}$, which dynamically depends on stratification and the $\mathbf{M}_{0}, \mathbf{M}_{2}$, and $\mathrm{M}_{4}$ water motion including GC and ESCO [see Eq. (20) and Eq. (23)], and contributes to the salinity distribution. Therefore, salinity, $A_{v_{\mathrm{M}_{2}}}$, GC and ESCO circulation also need to be solved iteratively. Initially, GC and salinity are calculated without considering the ESCO circulation, following Wei et al. (2017). Then, the flow velocity, tidal elevation, and salinity are substituted into Eq. (23) to calculate $A_{v_{\mathrm{M}_{2}}}$. With the information on $A_{v_{\mathrm{M}_{2}}}$, the ESCO circulation is calculated, which is used to calculate the new salinity field and GC. This procedure is iterated until the domain-averaged relative difference between the new tidally averaged salinity and the old salinity is again smaller than $0.1 \%$.

\section{b. Experiments design}

Parameters representative of the Blackwater estuary (in Essex, United Kingdom), which are typical for short estuaries, are used as a template in this study. Four experiments are conducted. In experiment I, Eq. (23) is used to calculate $A_{v_{\mathrm{M}_{2}}}$, where the influences of BGT, SIPS, and TWD on ATT are all considered. In experiments II, III, and IV, the individual contribution of BGT, SIPS, and TWD are investigated by considering contribution of each of these processes separately in the formulation of $A_{v_{\mathrm{M}_{2}}}$.

\section{1) DeFAult EXPERIMENT}

Parameters characteristic for the Blackwater estuary are considered in the default experiment. The estuary is $28 \mathrm{~km}$ long (with a weir located at the estuarine head, see Fig. 2a), and has a tidal amplitude of $\sim 2 \mathrm{~m}$, representative of short, mesotidal estuaries.

The geometry and bathymetry of the Blackwater estuary are simplified in the idealized model, see Fig. 2b. The width of the idealized Blackwater estuary is considered to exponentially decrease landward,

$$
B=B_{0} e^{\frac{-x}{L_{b}}},
$$

with $B_{0}$ the width at the mouth, and $L_{b}$ the estuarine convergence length. The water depth in the idealized estuary is described by

$$
H=H_{1}+\frac{x}{L} H_{2}+\left(H_{3}-\frac{x}{L} H_{3}\right) \exp \left(-C_{s} \frac{y^{2}}{B_{0}^{2}}\right),
$$

with $H_{1}, H_{2}$, and $H_{3}$ prescribed depth parameters, $C_{s}$ the shoal parameter, and $L$ the estuarine length; see Table 1 for their values. Comparing Figs. $2 \mathrm{a}$ and $2 \mathrm{~b}$, the idealized bathymetry is featured with a deeper channel in the middle and shallower shoals on each side, the main bathymetric feature of the real Blackwater estuary. The minimum water depth in the idealized case is $3.2 \mathrm{~m}$ (larger than the tidal amplitude), hence effects of intertidal flats are not considered. 
(a)
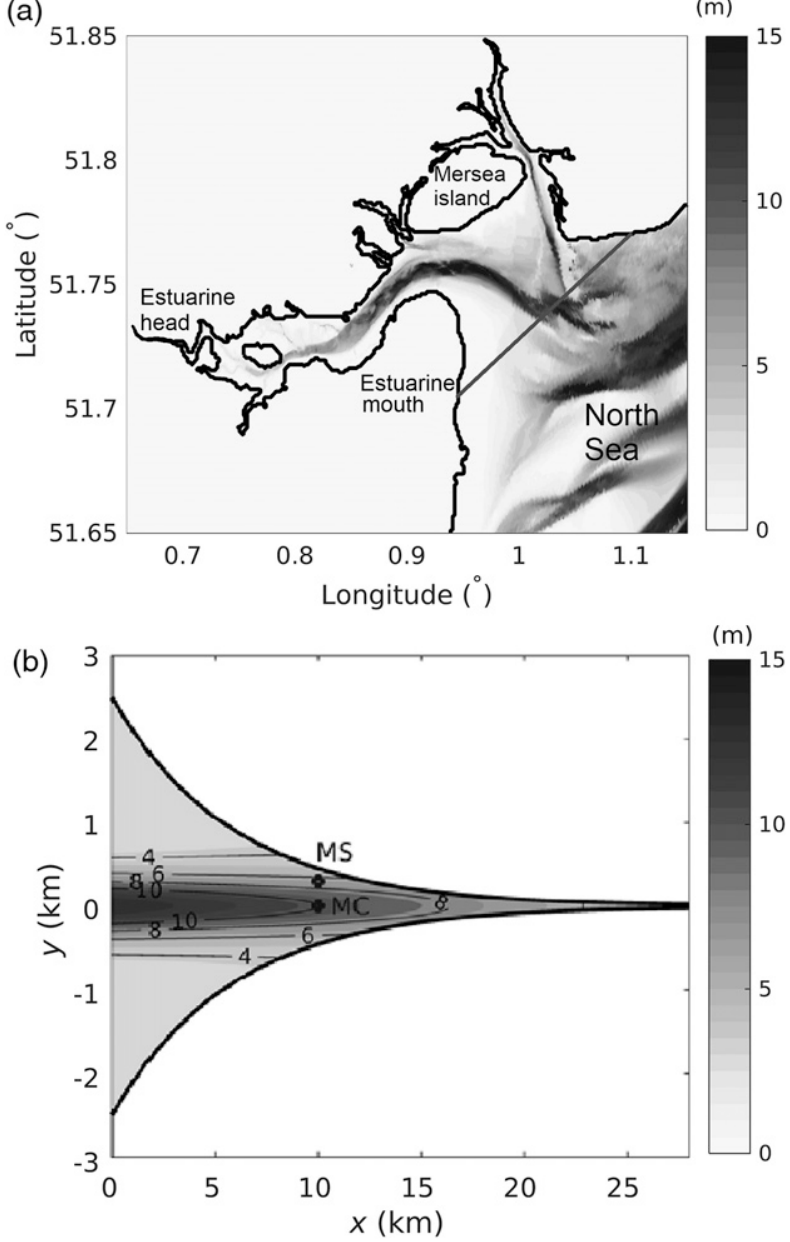

FIG. 2. Bathymetry of (a) the realistic Blackwater estuary and (b) the idealized estuary. The dots in (b) show different locations which represent the mid-estuary channel (MC) and shoal (MS), respectively. All water depths are relative to the undisturbed water level.

The dominant tidal constituent here is the $\mathrm{M}_{2}$ tidal constituent, with a tidal amplitude of $2 \mathrm{~m}$ at the mouth. The river discharge in the Blackwater estuary fluctuates from $\sim 1 \mathrm{~m}^{3} \mathrm{~s}^{-1}$ to up to $30 \mathrm{~m}^{3} \mathrm{~s}^{-1}$. During low river flow conditions, the estuary is mostly well mixed throughout the tidal cycle. During high river flows, the water column is well mixed during flood and weakly stratified during ebb. To focus on periodically stratified conditions, a constant river discharge $Q=20 \mathrm{~m}^{3} \mathrm{~s}^{-1}$ is used. Previous observations in this estuary show the water column can exhibit slightly unstable stratification during flood tides (Talbot 1967; Fox et al. 1999). To parameterize the enhanced turbulence due to convective instability in case of unstable stratification, the minimum depth-mean gradient Richardson number $\left(R_{i_{\min }}\right)$ is set to be -0.01 .

Influence of unresolved processes contributing to horizontal dispersion are parameterized by a horizontal eddy diffusivity $K_{h}$. This coefficient is related to the local cross-sectional area and the along-channel salinity gradient, according to Savenije
TABLE 1. Definitions of acronyms.

\begin{tabular}{ll}
\hline \hline Acronyms & \multicolumn{1}{c}{ Definition } \\
\hline AC & Advection/tidal rectification of the $\mathrm{M}_{2}$ tide \\
ACS & Along-channel tidal straining \\
ATT & Asymmetric tidal turbulence \\
BGT & Bottom-shear-generated turbulence \\
CCS & Across-channel tidal straining \\
DIFF & Horizontal diffusion \\
EF & External $\mathrm{M}_{4}$ tidal forcing \\
ESCO & Vertical eddy viscosity-shear covariance \\
GC & Gravitational circulation \\
NS & No-shear condition at the free surface \\
RD & River discharge \\
SIPS & Strain-induced periodic stratification \\
TRFSD & Tidal return flow that compensates Stokes drift \\
TWD & Tidal variations of water depth \\
\hline
\end{tabular}

(2015). For simplicity, it is assumed to linearly decrease with the estuarine width following Wei et al. (2017),

$$
K_{h}=K_{h_{0}}+C_{h} \frac{B}{B_{0}}
$$

with $C_{h}=10 \mathrm{~m}^{2} \mathrm{~s}^{-1}$. All other parameter values are given in Table 2 .

\section{2) SENSITIVITY EXPERIMENTS}

Equations (27)-(29) are respectively used in experiments IIIV (see Table 3), to investigate the individual contribution of BGT, SIPS, and TWD to the $\mathrm{M}_{2}$ vertical eddy viscosity and estuarine circulation (see section $3 b$ ).

\section{Results}

The patterns of the ATT, residual circulation, and salt transport in the idealized short estuary are shown in section $3 \mathrm{a}$. The individual contributions of SIPS, BGT, and TWD to ATT are quantified in section $3 \mathrm{~b}$. The interactions between ATT, water motion, and salinity distribution are unraveled in section $3 \mathrm{c}$. The semidiurnal and quarter-diurnal tidal properties are shown in appendix E.

\section{a. Varying patterns of vertical eddy viscosity, water motion, and salinity distribution}

\section{1) Vertical EDDY VISCOSITY}

The tidally averaged vertical eddy viscosity $A_{v_{\mathrm{M}_{0}}}$ and the depth-mean absolute amplitude of the semidiurnal tidal component $\left|\hat{A}_{v_{\mathrm{M}_{2}}}\right|$ both peak in the downstream channel and decrease landward as well as from the channel toward the shoals, as shown in Fig. 3. In most of the estuary, $\left|\hat{A}_{v_{\mathrm{M}_{2}}}\right|$ is smaller than $A_{v_{\mathrm{M}_{0}}}$. At a small region of the mid-estuary (at $x \approx 10 \mathrm{~km}$ ), however, $\left|\hat{A}_{v_{\mathrm{M}_{2}}}\right|$ slightly exceeds $A_{v_{\mathrm{M}_{0}}}$. This is caused by enhanced turbulence due to convective instabilities in case of unstable stratification (by allowing for negative gradient Richardson numbers with $R_{i_{\min }}=-0.01$ ), shown later in section $3 \mathrm{~b}$. The absolute amplitude of the semidiurnal eddy viscosity, $\left|\hat{A}_{v_{\mathrm{M}_{2}}}\right|$, is smaller than $A_{v_{\mathrm{M}_{0}}}$ throughout the estuary 
TABLE 2. Parameters for the idealized Blackwater estuary.

\begin{tabular}{|c|c|c|c|}
\hline Parameter & Definition & Value & Unit \\
\hline$L$ & Estuarine length & 28 & $\mathrm{~km}$ \\
\hline$L_{b}$ & Estuarine convergence length & 5.88 & $\mathrm{~km}$ \\
\hline$B_{0}$ & Width at the mouth & 5 & $\mathrm{~km}$ \\
\hline$H_{1}$ & Depth parameter & 3.2 & $\mathrm{~m}$ \\
\hline $\mathrm{H}_{2}$ & Depth parameter & 1.2 & $\mathrm{~m}$ \\
\hline$H_{3}$ & Depth parameter & 11.8 & $\mathrm{~m}$ \\
\hline$H_{m}$ & Mean water depth & 5.58 & $\mathrm{~m}$ \\
\hline$C_{S}$ & Shoal parameter & 436 & \\
\hline$Q$ & River discharge & 20 & $\mathrm{~m}^{3} \mathrm{~s}^{-1}$ \\
\hline$a_{\mathrm{M}_{0}}$ & $\mathrm{M}_{0}$ tidal amplitude at the mouth & 0.01 & $\mathrm{~m}$ \\
\hline$a_{\mathrm{M}_{2}}$ & $\mathrm{M}_{2}$ tidal amplitude at the mouth & 1.95 & $\mathrm{~m}$ \\
\hline$a_{\mathrm{M}_{4}}$ & $\mathrm{M}_{4}$ tidal amplitude at the mouth & 0.17 & $\mathrm{~m}$ \\
\hline$\sigma_{\mathrm{M}_{2}}$ & $\mathrm{M}_{2}$ tidal frequency & $\begin{array}{l}1.4045 \\
\times 10^{-4}\end{array}$ & $\mathrm{~s}^{-1}$ \\
\hline$\sigma_{\mathrm{M}_{4}}$ & $\mathrm{M}_{4}$ tidal frequency & $\begin{array}{l}2.8091 \\
\times 10^{-4}\end{array}$ & $\mathrm{~s}^{-1}$ \\
\hline$S_{m}$ & $\begin{array}{l}\text { Tidally averaged salinity at } \\
\text { the mouth }\end{array}$ & 35 & psu \\
\hline$\varphi_{\mathrm{M}_{2}}$ & Phase of the $\mathrm{M}_{2}$ tide at mouth & 0 & $\circ$ \\
\hline$\varphi_{\mathrm{M}_{4}}$ & Phase of the $\mathrm{M}_{4}$ tide at mouth & -225.79 & $\circ$ \\
\hline$S^{N_{4}}$ & Partial slip parameter & 0.02 & $\mathrm{~m}^{-1} \mathrm{~s}^{-1}$ \\
\hline$F$ & Coriolis parameter & $10^{-4}$ & $\mathrm{~ms}^{-1}$ \\
\hline$K_{h_{0}}$ & $\begin{array}{l}\text { Horizontal eddy viscosity and } \\
\text { diffusivity at the mouth }\end{array}$ & 30 & $\mathrm{~m}^{2} \mathrm{~s}^{-1}$ \\
\hline$R_{i_{\min }}$ & $\begin{array}{l}\text { Minimum gradient Richardson } \\
\text { number }\end{array}$ & -0.01 & \\
\hline
\end{tabular}

when considering $R_{i_{\min }}=0$ (not shown), highlighting the importance of convective instabilities to the generation of ATM.

The depth-mean phase of $A_{v_{\mathrm{M}_{2}}}$ shows remarkable lateral variability for $x<12 \mathrm{~km}$ and is almost constant across the channel further upstream. This is probably related to the water depth, which has strong lateral variations in the downstream and is almost laterally uniform in the upstream (Fig. 2b). In the central estuary ( $x \approx 10 \mathrm{~km}$ ), the depth-mean phase of $A_{v_{\mathrm{M}_{2}}}$ in the channel is in advance of that on the shoals by $\sim 180^{\circ}$, meaning $A_{v_{\mathrm{M}_{2}}}$ attains its maximum $\sim 6 \mathrm{~h}$ earlier than that on the shoals (Fig. $3 \mathrm{c}$ ).

\section{2) RESiduAl CIRCULATION}

The depth-mean total residual circulation is up to $0.08 \mathrm{~m} \mathrm{~s}^{-1}$ and consists of a landward flow in the channel and a seaward flow on the shoals (Fig. 4a). This total circulation is then decomposed into different components following Eq. (8). The contributions of the dominant residual circulation components are shown in Fig. 4. The depth-averaged gravitational circulation (GC), with a maximum velocity of $0.10 \mathrm{~m} \mathrm{~s}^{-1}$, is the largest estuarine circulation component, followed by ESCO circulation (up to $0.047 \mathrm{~m} \mathrm{~s}^{-1}$ ) and advection driven circulation (AC, up to $0.040 \mathrm{~m} \mathrm{~s}^{-1}$ ). The depth-averaged ESCO circulation shows an outflow in the channel and inflow on the shoals, contrasting the patterns of GC and AC. The differences in depth-averaged patterns between ESCO circulation and GC agree with findings of Scully and Friedrichs (2007) in the York River estuary. The residual circulation due to the no-shear surface condition, tidal return flow and river discharge are small, hence are not shown.
TABLE 3. Parameterizing formula for $A_{v}$ and $K_{v}$ in each experiment.

\begin{tabular}{lcccc}
\hline \hline Experiments & I & II & III & IV \\
\hline Formulation & Eq. (23) & Eq. (27) & Eq. (28) & Eq. (29) \\
\hline
\end{tabular}

Looking at a transect at $x=10 \mathrm{~km}$, the total residual circulation is apparent with a strong near-bottom inflow in the channel and near-surface outflow on the shoals (Fig. 4e). There is also a weak inflow in the upper layers of the channel, which does not agree with the "classical" estuarine circulation (with near-bottom inflow and near-surface outflow; see, e.g., Lerczak and Geyer 2004). This discrepancy is probably related to the overestimated vertical eddy viscosity near the surface, as a result of taking $\beta_{z}=1$ at all depths. In reality, turbulence has to vanish at the free surface, potentially increasing vertical shear (by reducing the vertical exchange of momentum) and enhancing the near-surface outflow due to tidal return flow, ESCO, and river discharge.

The cross-sectional distribution of GC is similar to the total circulation (Fig. 4f), highlighting the dominant role of GC in determining the structure of the total residual circulation in this idealized estuary. The patterns of GC are in agreement with existing analytical studies for large Ekman number (Kasai et al. 2000; Valle-Levinson et al. 2003; Huijts et al. 2009), where vertical eddy viscosity was assumed to be vertically uniform. ESCO circulation shows an outflow in the deep channel and inflow on the shoals (Fig. 4g), in agreement with model results of the Delaware estuary (Geyer et al. 2020). The patterns of GC and ESCO circulation are also consistent with the numerical results of Burchard et al. (2011) for small Simpson number. Advectively driven circulation shows inflow on the right side of the channel (looking landward) and outflow on the left side, consistent Huijts et al. (2009).

\section{3) SALINITY DISTRIBUTION AND TRANSPORT}

The tidally averaged salinity $S_{\mathrm{M}_{0}}$ decreases from 31 psu at the mouth to zero at $\sim 20 \mathrm{~km}$ from the mouth (Fig. 5a). The tidally averaged salinities are higher in the deep channel than on the shallow shoal. Due to Coriolis effects, $S_{\mathrm{M}_{0}}$ is larger on the right side of the estuary than on the left (looking toward the head). The amplitude of the top-to-bottom salinity difference peaks in the central estuary with a maximum value of $1.5 \mathrm{psu}$ (Fig. 5b). The amplitude of $S_{\mathrm{M}_{2}}$ also peaks in the central estuary, with a maximum value of 3.5 psu (Fig. 5c). The $\mathrm{M}_{2}$ tidal salinity has a small spatial phase difference (Fig. 5d), lagging behind the $\mathrm{M}_{2}$ velocity by $\sim 90^{\circ}$.

The relative importance of different processes to the residual salt transport in the idealized estuary is evaluated by calculating the cross-sectionally integrated residual salt transport due to each process, following Wei et al. (2017). Figure 6 shows the salt transport contributions due to tidal advection of salinity (TASF, red), ESCO circulation (ESCO, blue), gravitational circulation (GC, green), advection (AC, orange), shearfree surface (NS, yellow), tidal return flow (TRFSD, brown), horizontal diffusion (DIFF, pink), and river flow (RD, gray). In the idealized estuary, the residual salt balance is dominated by 

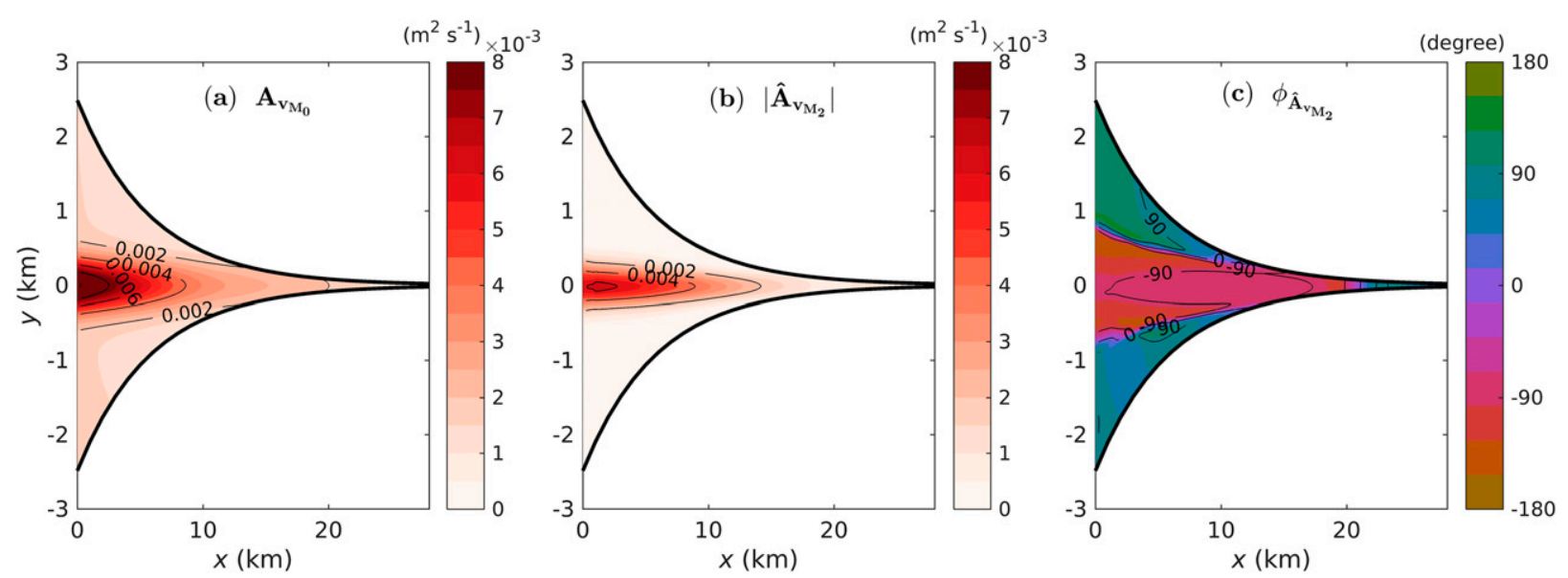

FIG. 3. The distribution of (a) the tidally averaged vertical eddy viscosity $A_{v_{\mathrm{M}_{0}}}$, (b) amplitude of the semidiurnal vertical eddy viscosity $\hat{A}_{v_{\mathrm{M}_{2}}}$, and (c) phase of the semidiurnal vertical eddy viscosity $\phi_{\hat{A}_{\mathrm{M}_{2}}}$.

the landward salt transport due to horizontal diffusion and the seaward transport due to river discharge. TASF and GC play an almost equally important role in transporting salt into the estuary, followed by AC. ESCO circulation, due to its reversed structure, tends to flush salt out of the estuary. The salt transport contributions due to all residual flow components, except river flow, vanish after the first $15 \mathrm{~km}$ because $S_{\mathrm{M}_{0}}$ becomes laterally uniform as a result of small lateral depth variations (Fig. 2b).

\section{b. Dissecting drivers of asymmetric tidal turbulence}

To understand the response of the vertical eddy viscosity $A_{v}$ to the flow and salinity changes, the tidal variations of vertical profiles of the along-channel velocity, salinity, gradient Richardson number $R_{i}$, and $A_{v}$ are plotted in Fig. 7 for two locations, representing the channel and shoal, respectively. The longitudinal velocity is flood dominant in the channel and ebb dominant on the shoal. At both locations, unstable stratification (with higher salinities at the top than the bottom) arises during the flood tide while stable stratification occurs during the ebb, consistent with previous observations in the Blackwater estuary (Talbot 1967). The unstable stratification results in negative values of gradient Richardson number $R_{i}$ during flood and positive values during ebb. Negative values of gradient Richardson number $\left(R_{i} \ll-0.01\right)$ are found in most of
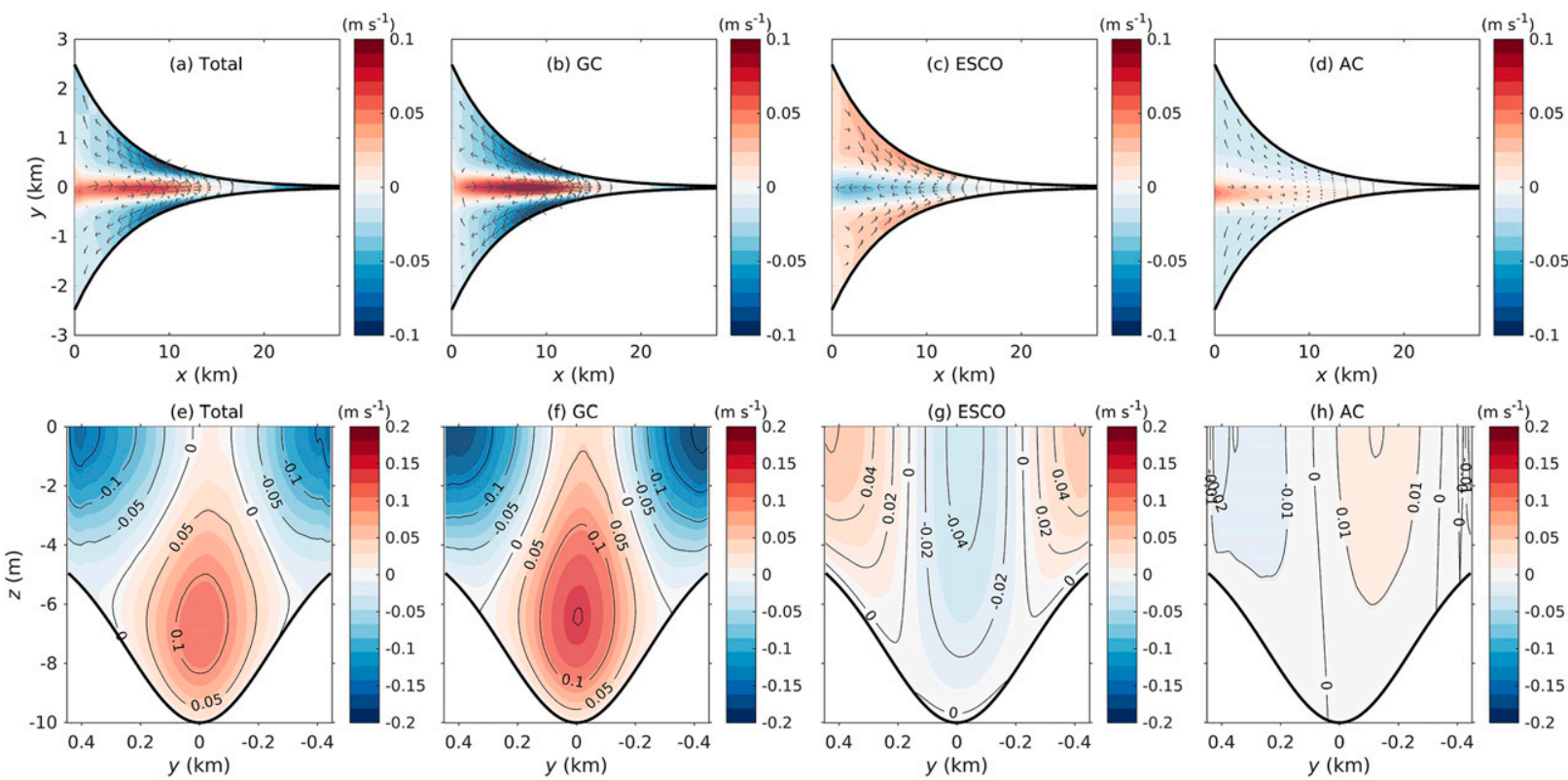

FIG. 4. (a),(e) Total residual circulation and individual contributions due to (b),(f) gravitational circulation, (c),(g) ESCO, and (d),(h) advection. The top panels show depth-mean horizontal velocities in the estuary and the bottom panels show cross-sectional distributions of longitudinal velocities at $x=10 \mathrm{~km}$. Arrows in (a)-(d) represent the depth-averaged horizontal velocity vectors including the lateral velocity component. 

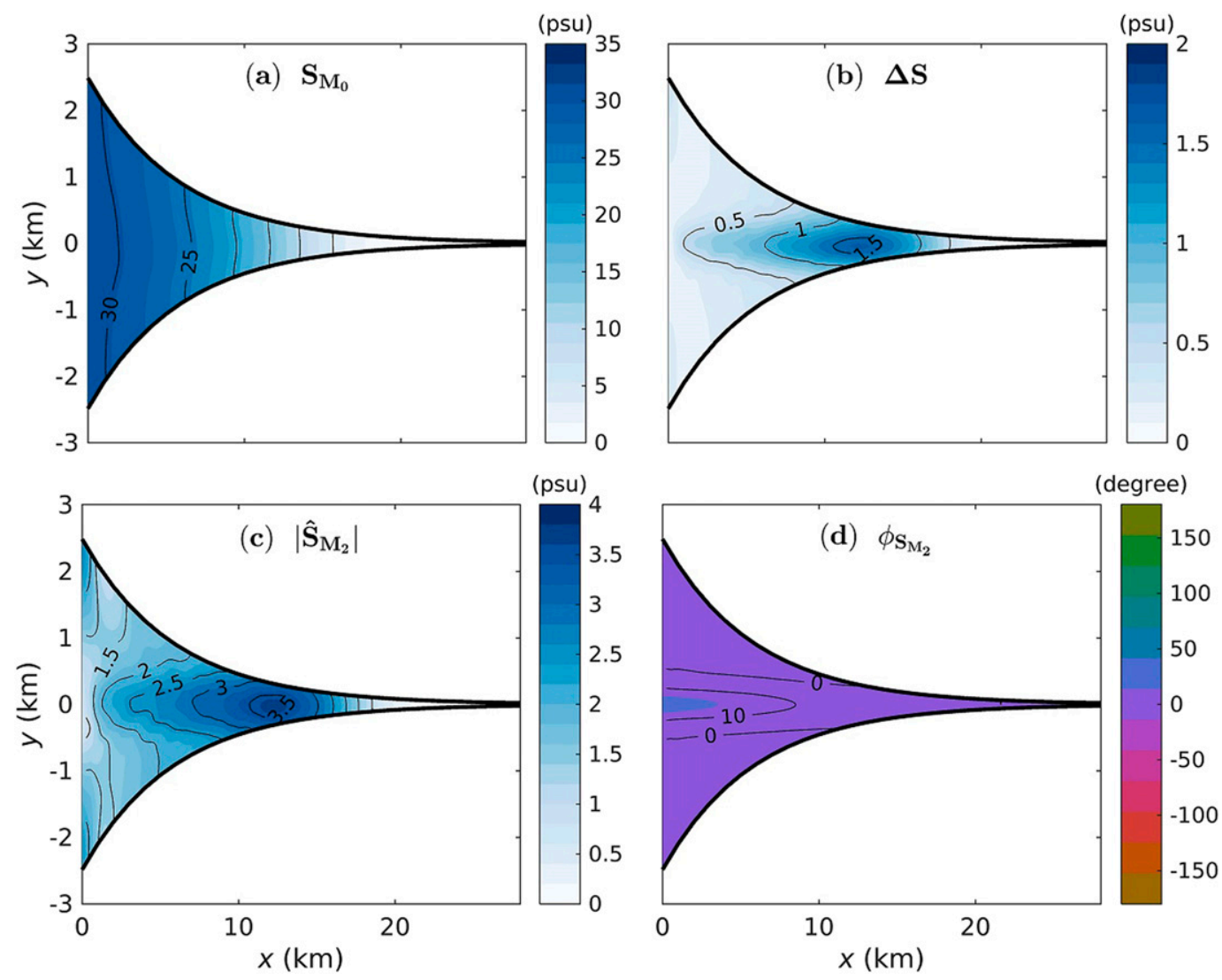

FIG. 5. (a) The residual salinity $S_{\mathrm{M}_{0}}$. (b) The absolute amplitude of the salinity difference between the top and the bottom: $\Delta S=\left|S_{\text {top }}-S_{\text {bottom }}\right|$. (c) Absolute amplitude and (d) phase of the depth-averaged semidiurnal salinity $S_{\mathrm{M}_{2}}$.

the water column under flood conditions. Since the vertical variations of $A_{v}$ can only originate from $R_{i}^{*}$ (by taking $\beta_{z}=1$ ), which is equal to $R_{i_{\min }}$ for $R_{i}<R_{i_{\min }}\left(R_{i_{\min }}=-0.01\right), A_{v}$ is vertically homogeneous in most of the water column (Fig. $7 \mathrm{~g}$ ). During ebb, large positive values of $R_{i}$ occur due to small vertical shear. As the vertical eddy viscosity is reversely related to $R_{i}$ when it is positive, $A_{v}$ approaches zero at depths with $R_{i}>$ 0.25 . This is consistent with the laboratory findings of Rohr et al. (1988) that turbulence decays for $R_{i}>R_{i_{c}}$, where $R_{i_{c}} \approx 0.25$ is the critical Richardson number. It is also found that $A_{v}$ is larger during flood than ebb in the channel but is larger during ebb on the shoal. This implies that the periodic stratification, which tends to increase $A_{v}$ during flood and reduce it during ebb at both locations [following Eq. (28)], is not always the dominant driver of asymmetric tidal turbulence (ATT), for example, on the shoal.

To identify the dominant driver(s) of ATT in this idealized estuary, the individual contributions of strain-induced periodic stratification (SIPS), asymmetric bottom-shear-generated turbulence (BGT) and tidal variation of water depth (TWD) to the semidiurnal variations of vertical eddy viscosity are calculated using Eqs. (27)-(29), respectively. Both SIPS and BGT are dominant drivers of ATT in this idealized estuary, whereas the contribution of TWD to ATT is small (Figs. 8a-c). The depth-mean amplitude of SIPS induced $\mathrm{M}_{2}$ vertical eddy viscosity, $\left|\hat{A}_{v_{\mathrm{M}_{2}}}^{\mathrm{SIPS}}\right|$, peaks at the mouth (Fig. 8a). It is larger in the channel than on the shoals near the mouth, and larger on the shoals than in the channel in the central estuary. The depthmean amplitude of BGT induced $\mathrm{M}_{2}$ vertical eddy viscosity,

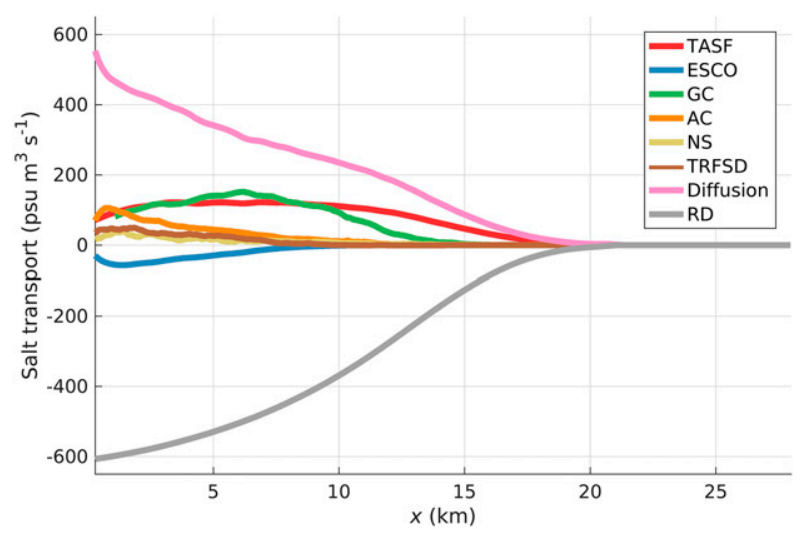

FIG. 6. The tidally averaged, along-channel salt transport integrated over the cross-section due to tidal advection of salinity (TASF, red), ESCO circulation (ESCO, blue), gravitational circulation (GC, green), advection (AC, orange), shear-free surface (NS, yellow), tidal return flow that compensates Stokes drift (TRFSD, brown), horizontal diffusion (DIFF, pink), and river flow (RD, gray). 

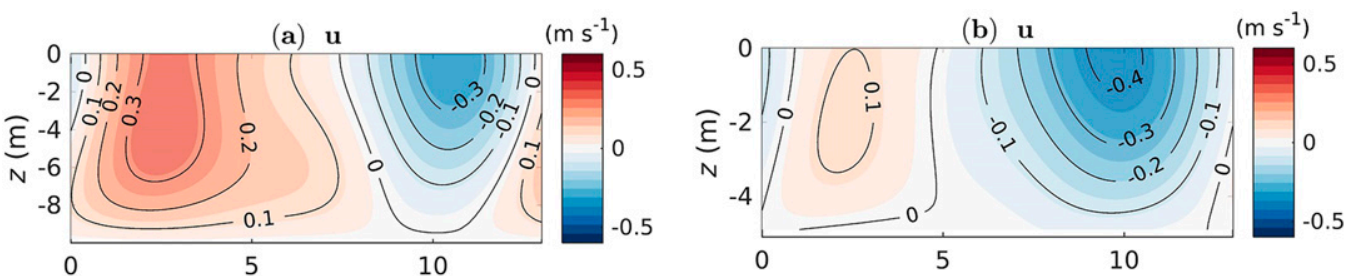

(c) $\mathrm{S}$

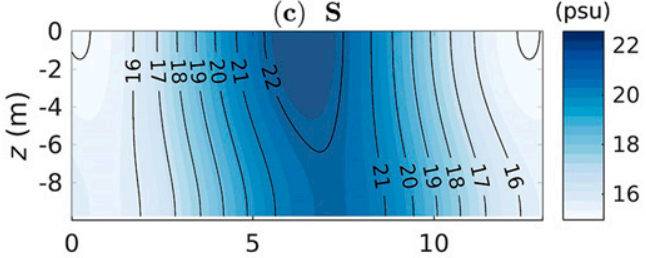

(d) $\mathbf{S}$
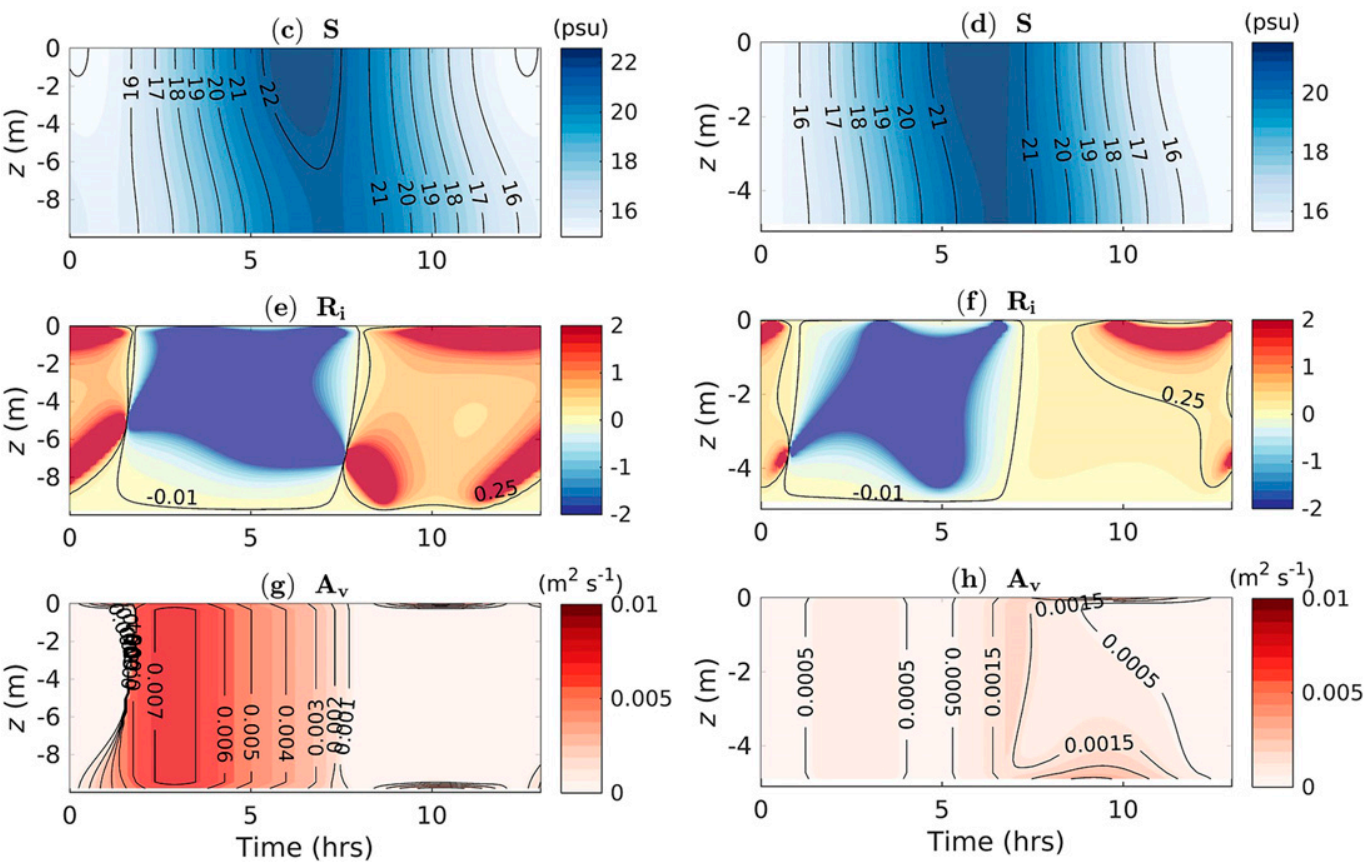

FIG. 7. Time series of the vertical distribution of (a),(b) along-channel velocity $u$; (c),(d) salinity $S$; (e),(f) gradient Richardson number $R_{i}$; and $(\mathrm{g}),(\mathrm{h})$ vertical eddy viscosity $A_{v}$ [calculated from Eq. (20)] at the (left) channel $(x=$ $10 \mathrm{~km}, y=0)$ and (right) shoal $(x=10 \mathrm{~km}, y=0.3 \mathrm{~km})$.

$\left|\hat{A}_{v_{\mathrm{M}_{2}}}^{\mathrm{BGT}}\right|$, also peaks near the mouth, and is larger in the channel than on the shoals throughout the estuary. The relative phase of the $\mathrm{M}_{2}$ vertical eddy viscosity due to all processes shows stronger channel-to-shoal than along-channel variability (Figs. $8 \mathrm{~d}-\mathrm{f}$ ). The phase of $A_{v_{\mathrm{M}_{2}}}^{\text {SIPS }}$ is between $-50^{\circ}$ and $-70^{\circ}$, with small cross-channel and along-channel variations (less than $20^{\circ}$, Fig. 8d). The phase of $A_{v_{\mathrm{M}_{2}}}^{\text {BGT }}$ slightly increases toward the head, but increases sharply from $-120^{\circ}$ in the channel to $120^{\circ}$ on the shoals (Fig. 8e). This means that $A_{v_{\mathrm{M}_{2}}}^{\mathrm{BGT}}$ changes by up to $8 \mathrm{~h}$ later on the shoals than in the channel. The phase of $A_{v_{\mathrm{M}_{2}}}^{\mathrm{TWD}}$ is less than $10^{\circ}$ everywhere, meaning it is almost synchronous with $\eta_{\mathrm{M}_{2}}$. These results imply that SIPS and BGT can act differently on ATT: both processes support flood-dominant eddy viscosity in the channel, but their contributions to ATT counteract each other on the shoals (shown in Fig. 7h).

\section{c. Interaction mechanisms between asymmetric tidal turbulence, water motion and salinity distribution}

The decomposition of ATT into different contributions allows a systematic investigation of the interacting mechanisms between ATT, water motion and salinity distribution. In this section, the interactions are shown by illustrating the influence of ATT on residual circulation [section 3c(1)] and salinity [section $3 c(2)$, and the impact of tidal straining and flow asymmetry on ATT [section $3 \mathrm{c}(3)]$.

\section{1) INFLUENCE OF ATT ON ESTUARINE CIRCULATION}

Asymmetric tidal turbulence, ATT, is essential to the generation of ESCO circulation. Because the ESCO circulation modulates the horizontal salinity gradients, it also indirectly influences GC. Figure 9 shows the cross-sectional distribution at $x=10 \mathrm{~km}$ of the along-channel GC (Figs. 9a-c) and ESCO circulation (Figs. 9d-f) in experiments II-IV as a result of the individual ATT contributions of strain-induced periodic stratification (SIPS, left panels), asymmetric bottom-sheargenerated turbulence (BGT, middle panels), and tidal variations of water depth (TWD, right panels). In all experiments, $\mathrm{GC}$ is stronger than the ESCO circulation. The spatial pattern of GC is consistent across the experiments, but its strength changes remarkably. When considering SIPS induced ATT only, the along-channel GC is up to $0.12 \mathrm{~m} \mathrm{~s}^{-1}$. It increases to $0.15 \mathrm{~m} \mathrm{~s}^{-1}$ when considering the BGT effects on ATT, and is up to $0.13 \mathrm{~m} \mathrm{~s}^{-1}$ (same as that in the default experiment) when considering the TWD effects only.

The ESCO circulation changes even more across the experiments, compared to GC. The ESCO induced by SIPS, 

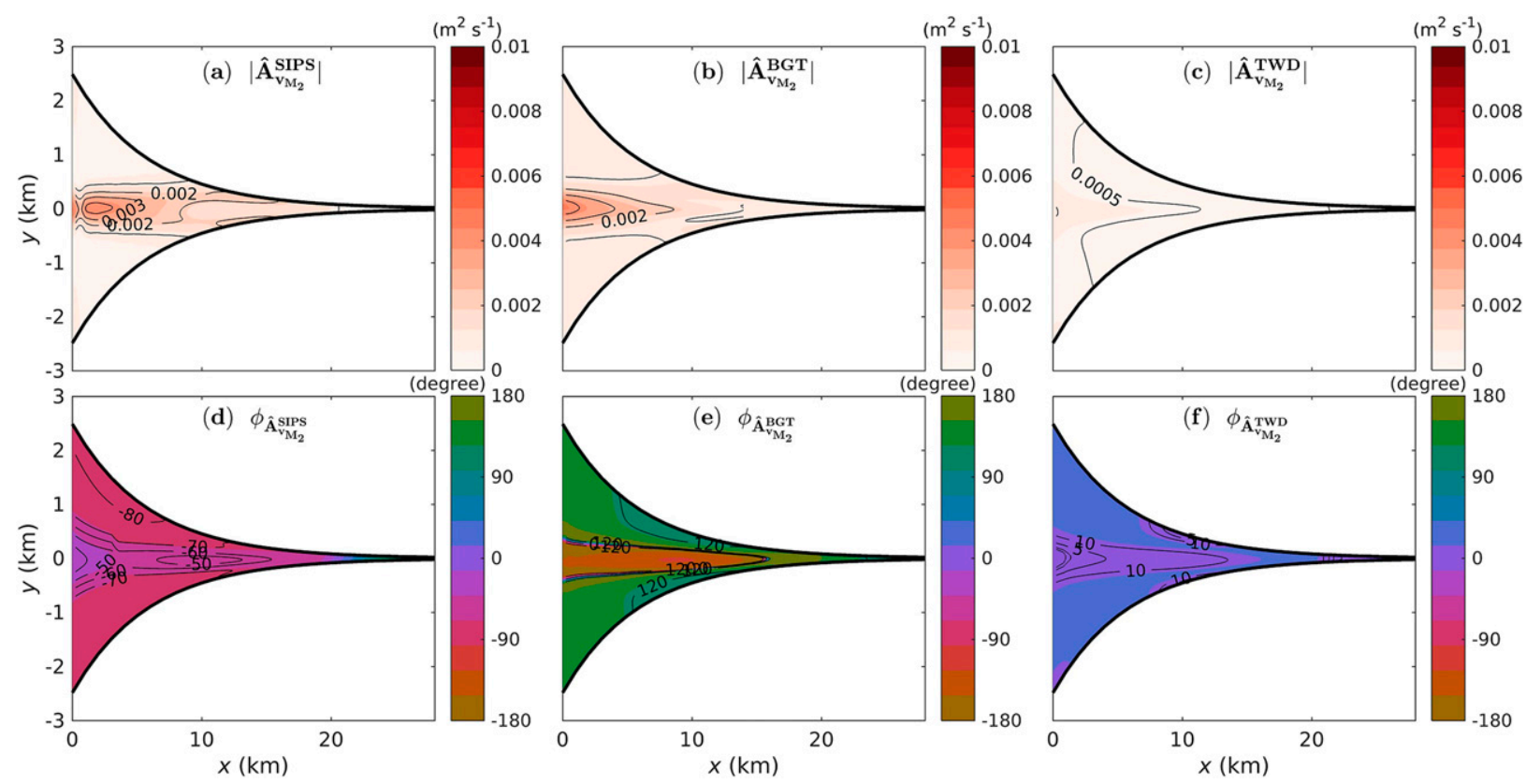

FIG. 8. Amplitude and phase of the semidiurnal vertical eddy viscosity caused by (a),(d) strain-induced periodic stratification, (b),(e) tidal asymmetries in the bottom-shear generated turbulence, and (c),(f) tidally varying water depth. The phases are relative to the semidiurnal tidal surface elevation at the mouth.

BGT, and TWD results in a maximal velocity of $0.05,0.1$, and $0.004 \mathrm{~m} \mathrm{~s}^{-1}$, respectively (Figs. 9d-f). Under the influence of BGT and TWD, the ESCO circulation yields an outflow in the channel and inflow on the shoals. The ESCO circulation caused by SIPS, however, generates an inflow in the channel and outflow on the shoals. That means, in this idealized estuary, the ESCO circulation caused by BGT and TWD act against GC to weaken the total estuarine circulation, while that driven by SIPS is in support of GC to strengthen the total estuarine circulation.

As illustrated by Burchard and Hetland (2010), the ESCO circulation at a certain position is reversely related to the ESCO-induced residual shear stress divided by the residual eddy viscosity $\left(\vartheta=\overline{A_{v_{\mathrm{M}_{2}}} \partial u_{\mathrm{M}_{2}} / \partial z} / A_{v_{\mathrm{M}_{0}}}\right)$ integrated from the bed to the vertical position of interest. Figures $9 \mathrm{~g}-\mathrm{i}$ show the cross-sectional distribution of $\vartheta$ when considering each of the three processes. Concerning the SIPS mechanism, positive values of $\vartheta$ are found across the section (Fig. 9g) which tend to drive seaward currents. Since the cross-sectionally integrated residual water transport has to vanish and $\vartheta$ is larger on the shoals than in the channel, the SIPS-induced ESCO consists of an outflow on the shoals and inflow in the channel. Concerning the BGT effects, however, $\vartheta$ is positive in the channel and negative on the shoals (Fig. 9h). Hence, this yields a strong outflow in the channel and inflow on the sides. ATT also contributes to a small quarter-diurnal tidal flow, as shown in Fig. E1a.

The contribution of SIPS to $A_{v_{\mathrm{M}_{2}}}$ and the ESCO circulation is sensitive to the minimum gradient Richardson number $R_{i_{\min }}$. Decreasing $R_{i_{\min }}$ will result in a smaller contribution of SIPS to the ESCO circulation because of smaller lateral variations of $\vartheta$.
This will then contribute to an enhanced ESCO circulation and a weaker total residual circulation (results not shown).

\section{2) INFLUENCE OF ATT ON SALINITY DISTRIBUTION}

The residual salinity distribution is strongly influenced by the residual eddy viscosity $A_{v_{\mathrm{M}_{0}}}$, because it significantly affects the TASF by controlling the magnitude and vertical structure of the semidiurnal tidal velocity and salinity (Wei et al. 2016), and influences the strength of all residual flow components. The semidiurnal component of vertical eddy diffusivity $K_{v_{\mathrm{M}_{2}}}$ does not directly contribute to the residual salinity distribution due to the vertically homogeneous nature of $S_{\mathrm{M}_{0}}$. The semidiurnal component of vertical eddy viscosity $A_{v_{\mathrm{M}_{2}}}$ influences the horizontal salinity distributions in two ways. First, as shown earlier in Fig. 6, the ESCO circulation due to the temporal correlations between vertical shear and $A_{v_{\mathrm{M}}}$, plays an important role in exporting salt out of the estuary and effectively redistributes salt. Moreover, the ESCO induced residual salt transport results in changes in horizontal salinity gradients, and yields an adapted gravitational circulation which again modifies the residual salinity distribution.

The influence of individual drivers of ATT (i.e., SIPS, BGT, and TWD) on salt transport can also be evaluated by recalculating the cross-sectionally integrated residual salt transport considering each process in separation (experiments II-IV). The SIPS induced ATT tends to import salt in the central estuary and export salt near the mouth through ESCO circulation (not shown). To balance this contribution, the GC induced salt transport is increased near the mouth, and decreased in the central estuary, compared to the default experiment. The BGT- and TWD-induced ATT exports salt throughout the 

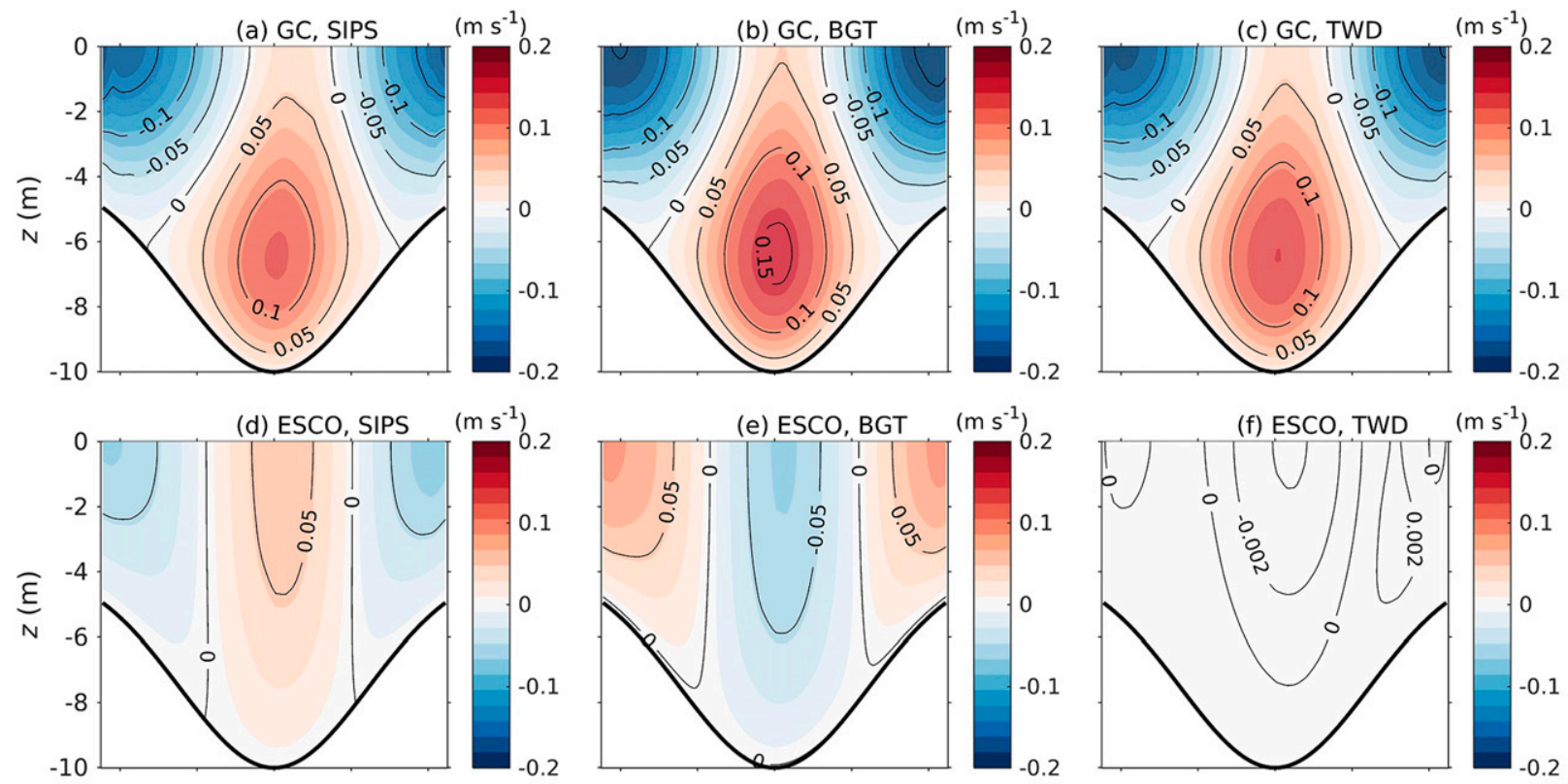

(e) ESCO, BGT
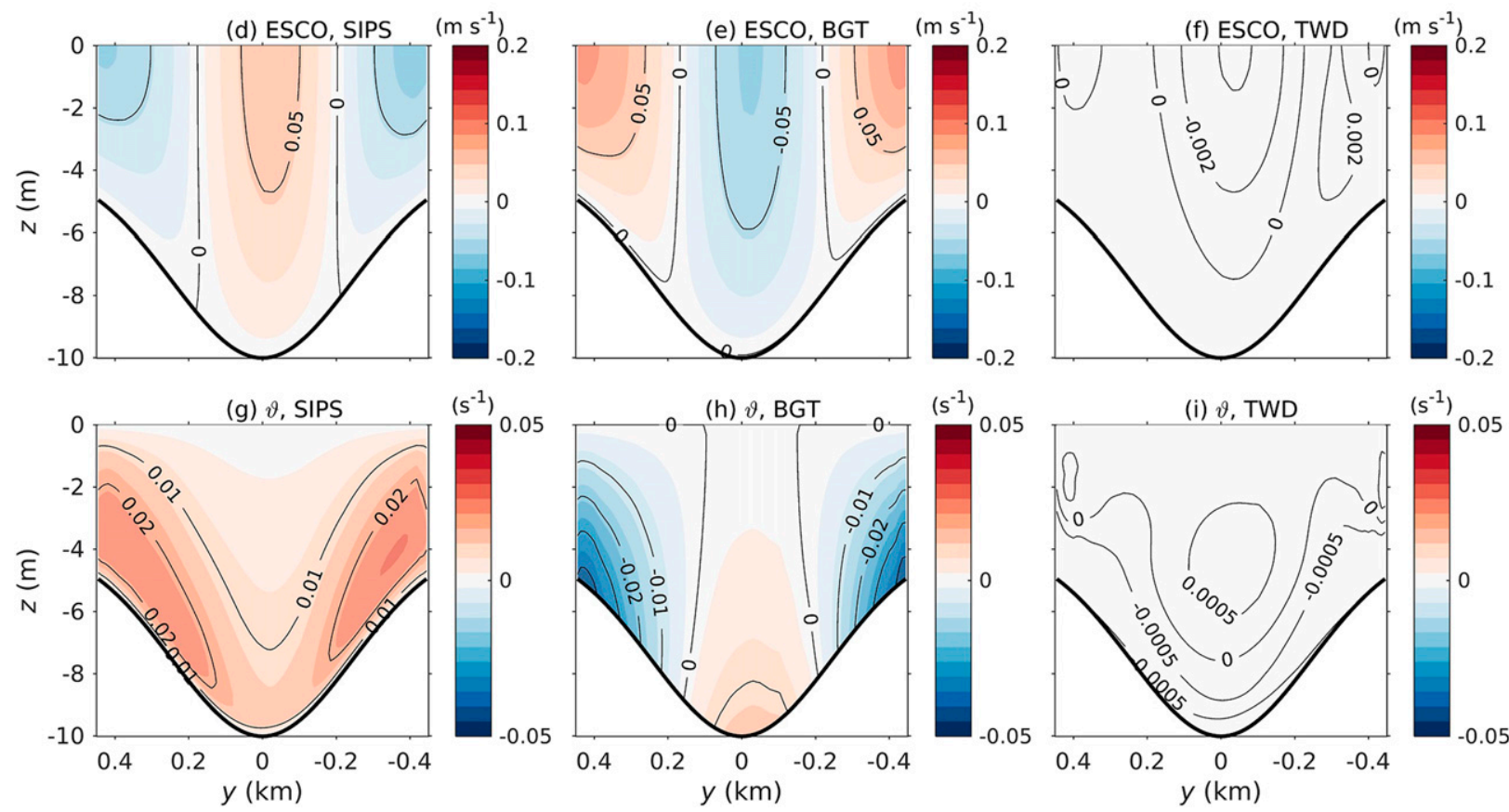

FIG. 9. Cross-sectional distribution of (a)-(c) gravitational circulation, (d)-(f) ESCO circulation, and (g)-(i) the ESCO-induced residual shear stress divided by the residual eddy viscosity, $\vartheta=\overline{A_{v_{\mathrm{M}_{2}}} \partial u_{\mathrm{M}_{2}} / \partial z} / A_{v_{\mathrm{M}_{0}}}$, when considering the individual contributions of (left) straininduced periodic stratification, (center) asymmetric bottom-shear-generated turbulence, and (right) tidal depth variation to the asymmetric tidal turbulence. The transect is located at $x=10 \mathrm{~km}$.

estuary, and effectively enhances the GC induced landward salt transport.

The salinity stratification is related to the vertical structure and amplitude of $S_{\mathrm{M}_{2}}$. The vertical structure of $S_{\mathrm{M}_{2}}$ is strongly determined by the residual eddy viscosity [see Eqs. (D7) and (D8)], and not affected by $A_{v_{\mathrm{M}_{2}}}$ or $K_{v_{\mathrm{M}_{2}}}$. The amplitude of $S_{\mathrm{M}_{2}}$ is determined by the horizontal gradients of the $\mathrm{M}_{2}$ sea surface elevation and residual salinity, hence is affected by ATT in the same way as shown above.

\section{3) IMPACT OF WATER MOTION AND SALINITY ON ASYMMETRIC TIDAL TURBULENCE}

In this section, the feedback of water motion and salinity distribution on ATT is explored. The driving mechanism of salinity stratification associated with the semidiurnal tide, which is key for the SIPS induced ATT, is investigated in section $3 c(3)(i)$. Influence of the residual circulation and quarter-diurnal tide on tidal asymmetric BGT, essential for $A_{v_{\mathrm{M}_{2}}}^{\mathrm{BGT}}$, are explored in section $3 \mathrm{c}(3)$ (ii). The contribution of
TWD to ATT is linearly proportional to the relative tidal elevation compared to the local water depth, and is not discussed in more detail.

\section{(i) Influence of the semidiurnal tide on asymmetric tidal turbulence}

Both $R_{i}^{*}$ and $A_{v_{\mathrm{M}_{2}}}^{\mathrm{SIPS}}$ are sensitive to the characteristics of the semidiurnal $\left(\mathrm{M}_{2}\right)$ tide because this tidal constituent controls the vertical shear and stratification. In the idealized estuary, the relative phase of stratification compared to the semidiurnal vertical shear, is almost constant across the estuary as the semidiurnal tide propagates at a pumping mode. Hence, $R_{i}^{*}$, as well as $A_{v_{\mathrm{M}_{2}}}^{\text {SIPS }}$, is primarily controlled by the amplitudes of the vertical shear and stratification. Due to relatively small alongchannel variations of the shear compared to stratification, the latter controls the longitudinal distribution of $A_{v_{\mathrm{M}_{2}}}^{\text {SIPS }}$.

The temporal changes of stratification can be described by taking the vertical derivative of the salinity equation. Since the leading-order salinity is time and depth independent, the 

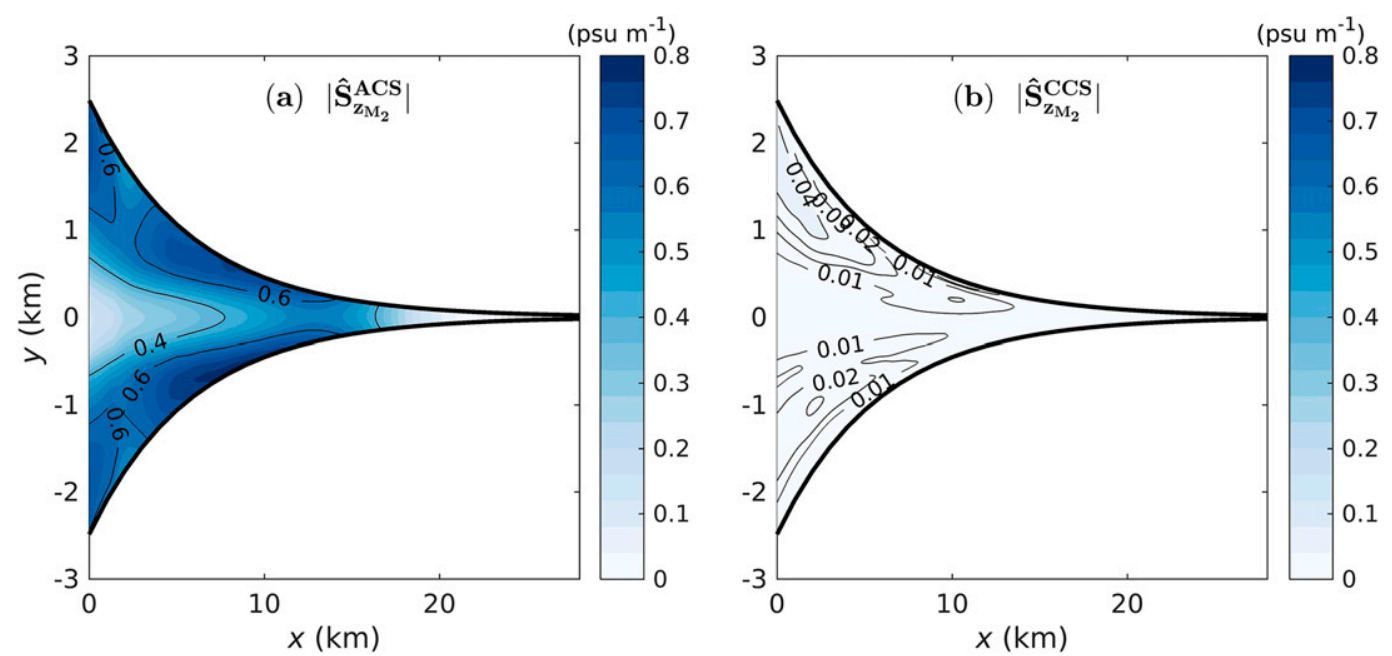

FIG. 10. Tidal amplitude of the depth-averaged vertical salinity gradients induced by (a) along-channel tidal straining (ACS) and (b) cross-channel tidal straining (CCS).

leading order equation of the vertical salinity gradient reduces to

$$
-\frac{\partial}{\partial t}\left(\frac{\partial S_{\mathrm{M}_{2}}}{\partial z}\right)+\frac{\partial^{2}}{\partial z^{2}}\left(K_{v_{\mathrm{M}_{0}}} \frac{\partial S_{\mathrm{M}_{2}}}{\partial z}\right)=\underbrace{\frac{\partial u_{\mathrm{M}_{2}}}{\partial z} \frac{\partial S_{\mathrm{M}_{0}}}{\partial x}}_{\text {ACS }}+\underbrace{\frac{\partial v_{\mathrm{M}_{2}}}{\partial z} \frac{\partial S_{\mathrm{M}_{0}}}{\partial y}}_{\text {CCS }} .
$$

Equation (33) indicates that, in periodically weakly stratified estuaries dominated by the semidiurnal tide, the temporal variations of stratification are caused by interactions between along-channel salinity gradients and the vertical shear due to along-channel semidiurnal tidal velocities, i.e., along-channel tidal straining (ACS), and interactions between cross-channel salinity gradients and the vertical shear due to cross-channel semidiurnal tidal velocities, i.e., cross-channel tidal straining (CCS). Note that in more strongly stratified conditions (not considered in this study), horizontal advection of vertical salinity gradients can also contribute to tidal variations of stratification (Scully and Geyer 2012).

Substituting the analytical expression of $u_{\mathrm{M}_{2}}$ and $v_{\mathrm{M}_{2}}$ [see details in appendix A and Kumar et al. (2016)] into Eq. (33), the analytical solution of the vertical salinity gradient can be derived:

$$
\begin{aligned}
\frac{\partial S_{\mathrm{M}_{2}}}{\partial z}= & \underbrace{S_{z z_{1}} \frac{\partial \eta_{\mathrm{M}_{2}}}{\partial x} \frac{\partial S_{\mathrm{M}_{0}}}{\partial x}+S_{z z_{2}} \frac{\partial \eta_{\mathrm{M}_{2}}}{\partial y} \frac{\partial S_{\mathrm{M}_{0}}}{\partial x}}_{S_{z_{\mathrm{M}_{2}}}^{\text {ACS }}} \\
& +\underbrace{S_{z z_{1}} \frac{\partial \eta_{\mathrm{M}_{2}}}{\partial y} \frac{\partial S_{\mathrm{M}_{0}}}{\partial y}-S_{z z_{2}} \frac{\partial \eta_{\mathrm{M}_{2}}}{\partial x} \frac{\partial S_{\mathrm{M}_{0}}}{\partial y}}_{S_{z_{\mathrm{M}_{2}}}^{\text {CCS }}} .
\end{aligned}
$$

Here $S_{z_{\mathrm{M}_{2}}}^{\mathrm{ACS}}$ and $S_{z_{\mathrm{M}_{2}}}^{\mathrm{CCS}}$ denote the vertical salinity gradient produced by ACS and CCS, respectively. Equation (34) shows the semidiurnal tide influences stratification in three ways.
First, the vertical profile of stratification, controlled by $S_{z z_{1}}$ and $S_{z z_{2}}$, is determined by the vertical structures of the $\mathrm{M}_{2}$ tidal currents and salinity, see details in appendix D. Second, stratification is linearly dependent on the horizontal gradients of the semidiurnal tidal elevation and $S_{\mathrm{M}_{0}}$. Last but not least, since TASF, resulting from advection of the semidiurnal tidal salinity by the semidiurnal tidal currents, contributes to the second largest landward residual salt transport (see Fig. 6), the semidiurnal tide significantly influences stratification also by controlling the horizontal salinity gradients.

The amplitudes of the depth-mean $S_{z_{\mathrm{M}_{2}}}^{\mathrm{ACS}}$ and $S_{z_{\mathrm{M}_{2}}}^{\mathrm{CCS}}$ in the idealized estuary are shown in Fig. 10. Here, large values of $\left|\hat{S}_{z_{\mathrm{M}_{2}}}^{\mathrm{ACS}}\right|$ and $\left|\hat{S}_{z_{\mathrm{M}_{2}}}^{C C S}\right|$ indicate large intratidal variations of stratification, which facilitate large fluctuations of $A_{v_{\mathrm{M}_{2}}}^{\text {SIPS }}$. In most of the estuary, $\left|\hat{S}_{z_{\mathrm{M}_{2}}}^{\mathrm{ACS}}\right|$, with a maximum magnitude of $0.5 \mathrm{psu} \mathrm{m}^{-1}$, is larger than $\left|\hat{S}_{z_{\mathrm{M}_{2}}}^{\mathrm{CCS}}\right|$, which is less than $0.05 \mathrm{psu} \mathrm{m}^{-1}$. It implies that the impact of ACS on the intratidal variations of $A_{v_{\mathrm{M}_{2}}}^{\text {SIPS }}$ (through $R_{i}^{*}$ ) is more important than that of CCS in the idealized estuary. Note here the patterns of $\left|\hat{S}_{z_{\mathrm{M}_{2}}}^{\text {ACS }}\right|$ and $\left|\hat{S}_{z_{\mathrm{M}_{2}}}^{\mathrm{CCS}}\right|$ are different from that of the top-to-bottom salinity difference (Fig. 5b) due to the spatial variations in bathymetry. Influences of ACS and CCS on ATT are also different due to their different phasing (not shown). The CCS effect, although small in this idealized estuary, can become significant in cases of sharp lateral depth variations, strong channel curvature, or large channel width.

\section{(ii) Influence of residual circulation and quarter-diurnal tide on asymmetric tidal turbulence}

The residual circulation plays an important role in the residual salt transport, hence affecting the horizontal salinity gradients and stratification, and modulating ATT through $A_{v_{\mathrm{M}_{2}}}^{\text {SIPS }}$. The residual circulation also contributes to the bottom-shear-generated turbulence, BGT, hence modulating ATT through $A_{v_{\mathrm{M}_{2}}}^{\mathrm{BGT}}$. The quarter-diurnal tide does not directly contribute to the residual salt transport or stratification, and is unimportant with regard to 


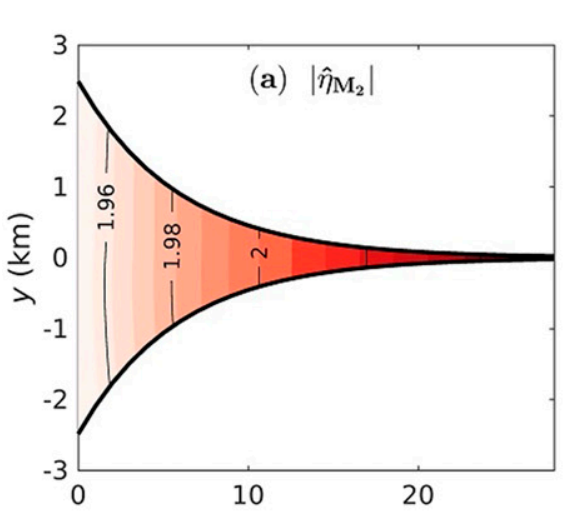

(m)
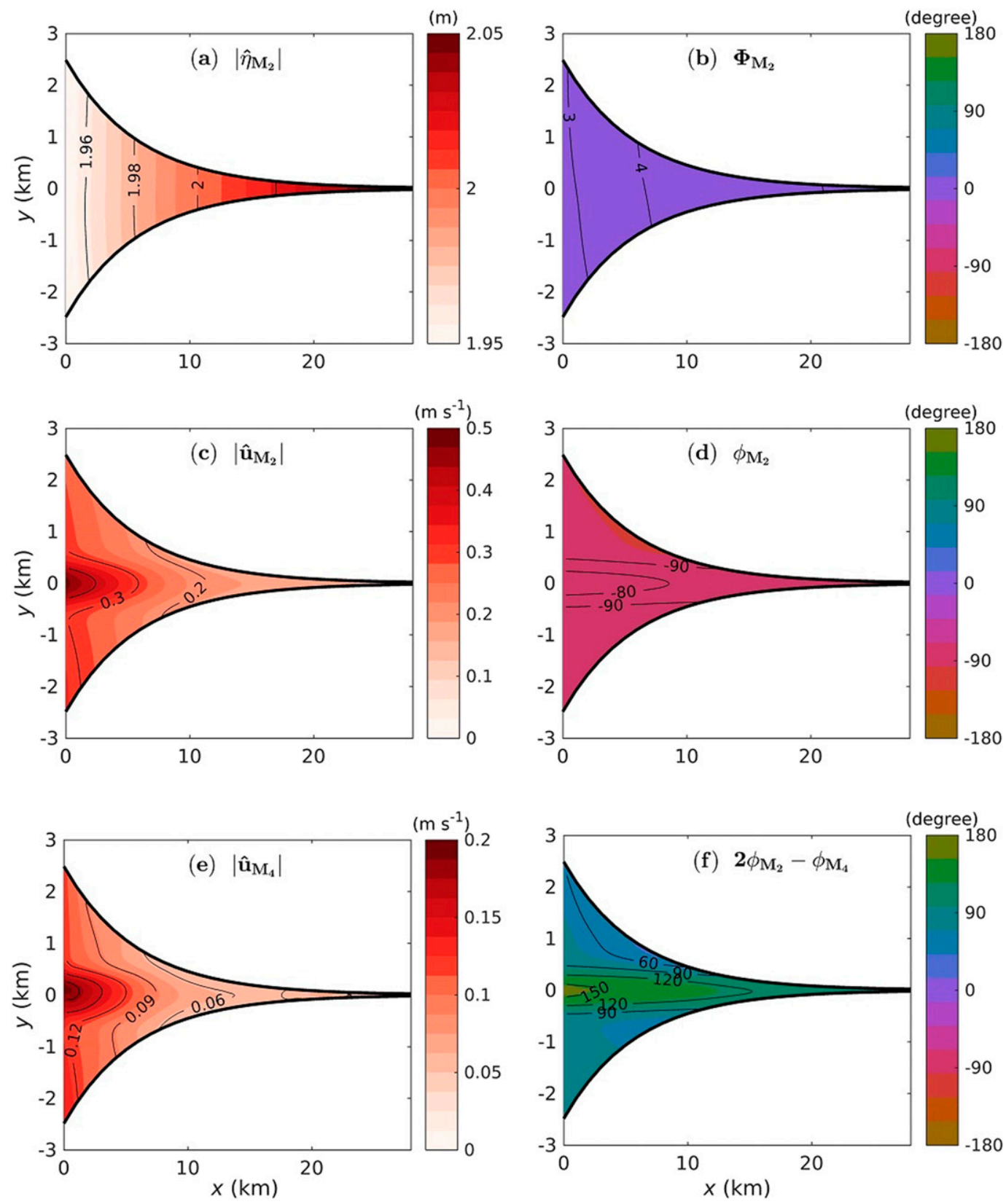

FIG. 11. Amplitude and phase of (a),(b) the semidiurnal tidal surface elevation $\eta_{\mathrm{M}_{2}}$, and (c),(d) the depth-mean along-channel semidiurnal tidal velocities. (e) Amplitude of the depth-mean longitudinal velocity at the quarterdiurnal tidal frequency. (f) Relative phase of the depth-mean quarter-diurnal tidal velocity compared to the semidiurnal tidal velocity: $\Delta \phi=2 \phi_{\mathrm{M}_{2}}-\phi_{\mathrm{M}_{4}}$. The phase and amplitude of $\eta_{\mathrm{M}_{2}}, u_{\mathrm{M}_{2}}$, and $u_{\mathrm{M}_{4}}$ are derived by noting $\eta_{\mathrm{M}_{2}}=\Re\left[\left|\eta_{\mathrm{M}_{2}}\right| e^{i\left(\sigma_{\mathrm{M}_{2}} t-\Phi_{\mathrm{M}_{2}}\right)}\right], u_{\mathrm{M}_{2}}=\Re\left[\left|u_{\mathrm{M}_{2}}\right| e^{i\left(\sigma_{\mathrm{M}_{2}} t-\phi_{\mathrm{M}_{2}}\right)}\right]$, and $u_{\mathrm{M}_{4}}=\Re\left[\left|u_{\mathrm{M}_{4}}\right| e^{i\left(\sigma_{\mathrm{M}_{4}} t^{2} \phi_{\mathrm{M}_{4}}\right)}\right]$. All phases are relative to the semidiurnal tidal elevation at the mouth.

$A_{v_{\mathrm{M}_{2}}}^{\mathrm{SIPS}}$. However, it can significantly affect the tidal asymmetries in the currents, and contribute to ATT through $A_{v_{\mathrm{M}}}^{\mathrm{BGT}}$.

The residual circulation and quarter-diurnal tidal velocity are of the same order of magnitude in most of estuary (see Figs. 4a,e and 11e), suggesting that both components can play an important role in generating asymmetries in BGT and contribute to $A_{v_{\mathrm{M}_{2}}}^{\mathrm{BGT}}$. The residual circulation tends to promote flood dominance in the channel and ebb dominance on the shoals. In contrast, the quarter-diurnal tide tends to promote ebb dominance in the channel and flood dominance on the shoals (Fig. 11f). Therefore, the flood-ebb asymmetry in BGT strongly depends on the relative importance of contributions of the residual circulation and quarter-diurnal tide to the tidal velocity asymmetry. In the deep channel and on the shallow 
shoals, residual circulation dominates the tidal velocity asymmetry, hence during flood $A_{v_{\mathrm{M}_{2}}}^{\mathrm{BGT}}$ is positive in the channel and negative on the shoals, and vice versa during ebb. Over the shoulders of the channel, residual circulation is weak and the quarter-diurnal tidal currents dominate the tidal velocity asymmetry, hence the phase of $A_{v_{\mathrm{M}_{2}}}^{\mathrm{BGT}}$ is close to $\Delta \phi$ there.

\section{Discussion}

To facilitate a comparison of our semi-analytic model results with existing numerical studies that focus on long estuaries, the model was also applied to a long estuary with a length of $100 \mathrm{~km}$ (results not shown). The estuarine convergence length is reduced to keep the width at the mouth and the river boundary the same as those in the short estuary. In this case, the ESCO circulation is stronger than gravitational circulation, GC. This opposes the results for the short estuary, where GC is stronger than the ESCO circulation (see Figs. 4b,c). This difference between the short and long estuary seems to agree with the cross-sectional model results of Burchard et al. (2011) for large and small Simpson number $\left(S_{i}\right)$, respectively. They found that the residual circulation is dominated by GC for large $S_{i}$ but dominated by ESCO for small $S_{i}$. This agreement is probably related to the larger $S_{i}$ in the short estuary due to relatively large along-channel salinity gradients when compared to the long estuary.

The different asymmetric tidal turbulence and ESCO circulation patterns caused by strain-induced periodic stratification (SIPS) and bottom-shear-generated turbulence (BGT) shown in this study indicate that the variable ESCO circulation patterns found in previous studies may be related to different processes being dominant in different systems. In case ATT is dominated by SIPS, ESCO circulation and GC follow similar patterns. In case ATT is dominated by BGT, the structure of ESCO circulation depends on the tidal asymmetries in BGT. The tidal asymmetries in BGT, due to their dependence on the residual and quarter-diurnal tidal currents, are significantly influenced by estuarine topography, geometry, length, and forcing (Jay 1991; Friedrichs and Aubrey 1994; Ridderinkhof et al. 2014).

Although the semi-analytical model has some limitations with regard to complex estuarine environments due to the adoption of several assumptions [e.g., weak quarter-diurnal variations of turbulence, linearized bottom friction, vertically homogeneous residual vertical eddy viscosity, unity PrandtlSchmidt number (Pr)], it does provide valuable insights into the dynamic interacting barotropic and baroclinic processes. Nevertheless, these assumptions can result in quantitatively different results when compared to reality.

1) By focusing on weakly stratified estuaries in this study, it is reasonable to assume that the semidiurnal vertical eddy viscosity is an order of magnitude smaller than the residual viscosity [Eq. (11)]. By making these assumptions, the tidal variations of vertical eddy viscosity and diffusivity (asymmetric tidal turbulence, ATT) do not directly influence the semidiurnal tide, GC, or the residual salinity. Nevertheless, ATT can indirectly influence GC and the residual salinity through the ESCO-induced salt transport. In partially stratified estuaries, where the residual and semidiurnal salinities are within the same order of magnitude, ATT can significantly influence the water motion and salinity at all tidal frequencies. In those systems, the influence of ATT on estuarine circulation and salt transport can be even stronger (see, e.g., Dijkstra et al. 2017).

2) By tuning the friction parameters to obtain the best fit of the observed sea level and velocities, the linearized bed friction assumption allows good reproduction of the residual and dominant tidal bed stresses (Geyer et al. 2000; Li et al. 2004), but the overtide and its induced tidal asymmetry are not well reproduced (Friedrichs and Aubrey 1994). Therefore, the relative importance of the bottom-shear generated ATT, ESCO circulation, GC, and salt transport can differ quantitatively from those when considering a more realistic quadratic bottom friction.

3) The tidally averaged vertical eddy viscosity and diffusivity are assumed to be vertically uniform in our model (by taking $\beta_{z}=1$ ). In reality, these coefficients can change significantly in the vertical (Peters 1997; Huguenard et al. 2015; Ross et al. 2019). Considering vanishing turbulence at the free surface and the bottom, for example, will probably increase near-surface seaward currents and reduce them near the bottom, increase stratification, reduce lateral exchange, and strengthen the along-channel GC. Consequently, the individual contributions of SIPS and BGT to the generation of ATT and ESCO circulation will probably be increased.

4) A unity Pr, which is observed in salt wedge estuaries (Geyer and Smith 1987; Holleman et al. 2016), was considered in this study for simplicity. In reality, $\operatorname{Pr}$ is related to the gradient Richardson number, according to Stacey et al. (1999). They found that Pr reduces to 0.7 when the gradient Richardson number approaches zero. Therefore, by assuming $\operatorname{Pr}=1$, we overestimated the vertical eddy diffusivity particularly during the flood tide. This probably has led to underestimated unstable stratification and underestimated contribution of strain-induced periodic stratification to the asymmetric tidal turbulence and ESCO circulation.

\section{Conclusions}

Focusing on asymmetric tidal turbulence (ATT) at the semidiurnal $\left(\mathrm{M}_{2}\right)$ tidal frequency, a semi-analytical model was developed to study the dynamic interactions between asymmetric tidal turbulence (parameterized by the $\mathrm{M}_{2}$ variations of vertical eddy viscosity and diffusivity), water motion and salinity in periodically, weakly stratified estuaries. This model was applied to an idealized short estuary. Results show that, gravitational circulation (GC) is the most important estuarine circulation component, followed by the residual circulation related to ATT and eddy viscosity shear covariance (ESCO), and the advectively driven circulation (AC). The depth-mean ESCO circulation exhibits a reversed pattern compared to GC and $\mathrm{AC}$, resulting in a significant residual seaward salt transport. This contrasts the significant landward salt transport induced by GC. Tidal pumping (due to advection of salinity by semidiurnal tidal currents) also plays an important role in transporting salt landward in this short estuary.

Asymmetric tidal turbulence influences estuarine circulation not only by being essential to the generation of the ESCO 
circulation, but also by modulating the horizontal salinity gradients (due to the ESCO generated salt transport), hence affecting GC. It is found that the impact of ATT on residual circulation and salt transport strongly depends on the dominant mechanisms generating ATT, namely, strain-induced periodic stratification (SIPS) and asymmetric bottom-shear-generated turbulence (BGT). SIPS increases vertical eddy viscosity during flood and reduce it during ebb, and this effect is more significant on the shoals than in the channel. This results in an ESCO circulation with almost the same depth-averaged structure as GC, and tends to transport salt landward. This transport tends to reduce longitudinal salinity gradients and hence weakens GC. BGT yields a higher eddy viscosity during flood in the channel and during ebb over the shoals. This results in a reversed ESCO circulation with depth-averaged patterns opposite to GC. This ESCO circulation acts to increase longitudinal salinity gradients and hence enhances GC.

The feedback of water motion and salinity distribution on ATT is also revealed. The semidiurnal tide predominantly controls the ATT generated by SIPS because this tidal constituent controls the vertical shear and stratification. Due to the dependence of stratification on horizontal salinity gradients, the semidiurnal tide also indirectly affects ATT by modulating these gradients due to the important landward salt transport contribution induced by tidal pumping. Residual circulation and the quarter-diurnal tide both contribute significantly to tidal asymmetries in velocities, hence strongly influencing the ATT induced by BGT. Due to strong tidal velocity asymmetries and weak stratification in this idealized short estuary, the BGT effects dominate over the SIPS effects in the generation of ATT which explains the reversed structure of the total ESCO circulation. These findings highlight the influence of different turbulence sources on ATT, hydro- and salinity dynamics can differ significantly. Since the relative importance of these sources are strongly dependent on estuarine bathymetry, geometry and forcing, the techniques developed here can be used to gain a general understanding of turbulence variations, and their influence and dependence on the estuarine circulation and stratification in realistic estuaries.

Acknowledgments. We acknowledge funding from the Natural Environment Research Council through the BLUEcoast project (NE/N015894/1). HMS and LOA also acknowledge funding to the SUPREME project from NWO in the Netherlands and the Newton Fund via the Engineering and Physical Sciences Research Council (Grant ALWSD.2016.015 in the Netherlands, and Grant EP/R024480/1 in the United Kingdom). MEW was partially supported by Chilean Fondecyt project 11191077 . This work used the NOC cluster MOBIUS and the ARCHER U.K. National Supercomputing Service (http://www.archer.ac.uk). We appreciate the constructive comments from two anonymous reviewers, which significantly improved our paper. All data used in this paper are available on Zenodo (https://doi.org/10.5281/zenodo.4666030).

\section{APPENDIX A}

\section{Leading-Order Water Motion}

The leading-order water motion follow from the $\mathrm{M}_{2}$ components of the shallow water equations:

$$
\begin{aligned}
\frac{\partial u_{\mathrm{M}_{2}}}{\partial x}+\frac{\partial v_{\mathrm{M}_{2}}}{\partial y}+\frac{\partial w_{\mathrm{M}_{2}}}{\partial z} & =0, \\
\frac{\partial u_{\mathrm{M}_{2}}}{\partial t}-f v_{\mathrm{M}_{2}} & =-g \frac{\partial \eta_{\mathrm{M}_{2}}}{\partial x}+A_{v_{\mathrm{M}_{0}}} \frac{\partial^{2} u_{\mathrm{M}_{2}}}{\partial z^{2}}, \\
\frac{\partial v_{\mathrm{M}_{2}}}{\partial t}+f u_{\mathrm{M}_{2}} & =-g \frac{\partial \eta_{\mathrm{M}_{2}}}{\partial y}+A_{v_{\mathrm{M}_{0}}} \frac{\partial^{2} v_{\mathrm{M}_{2}}}{\partial z^{2}},
\end{aligned}
$$

with boundary conditions

$$
\begin{gathered}
\eta_{\mathrm{M}_{2}}=a_{\mathrm{M}_{2}} \text { at } x=0, \\
{\left[\int_{-H}^{0}\left(u_{\mathrm{M}_{2}}, v_{\mathrm{M}_{2}}\right) d z\right] \cdot \mathbf{n}_{h}=0 \quad \text { at } \quad x=L,} \\
{\left[\int_{-H}^{0}\left(u_{\mathrm{M}_{2}}, v_{\mathrm{M}_{2}}\right) d z\right] \cdot \mathbf{n}_{h}=0 \quad \text { at } \quad y= \pm B / 2,} \\
A_{v_{\mathrm{M}_{0}}}\left(\frac{\partial u_{\mathrm{M}_{2}}}{\partial z}, \frac{\partial v_{\mathrm{M}_{2}}}{\partial z}\right)=0 \quad \text { at } \quad z=0, \\
w_{\mathrm{M}_{2}}=-u_{\mathrm{M}_{2}} \frac{\partial H}{\partial x}-v_{\mathrm{M}_{2}} \frac{\partial H}{\partial y} \quad \text { at } \quad z=-H, \\
A_{v_{\mathrm{M}_{0}}}\left(\frac{\partial u_{\mathrm{M}_{2}}}{\partial z}, \frac{\partial v_{\mathrm{M}_{2}}}{\partial z}\right)=s\left(u_{\mathrm{M}_{2}}, v_{\mathrm{M}_{2}}\right) \quad \text { at } \quad z=0, H .
\end{gathered}
$$

For a given $A_{v_{\mathrm{M}_{0}}}$, the leading-order water motion can be calculated following Kumar et al. (2016). Since $A_{v_{\mathrm{M}_{0}}}$ depends on the leading-order water motion, an iterative procedure is taken to solve the $\mathrm{M}_{2}$ tidal flow and $A_{v_{\mathrm{M}_{0}}}$, see section $2 \mathrm{a}(5)$.

\section{APPENDIX B}

\section{First-Order Water Motion}

\section{a. Governing equations}

The first-order residual flow contains two tidal frequencies: $\mathrm{M}_{0}$ and $\mathrm{M}_{4}$. The governing equations for residual flows at these two frequencies are derived by considering the tidal average or the $\mathrm{M}_{4}$ component of the shallow water equations:

$$
\begin{aligned}
& \frac{\partial u_{\mathrm{M}_{j}}}{\partial x}+\frac{\partial v_{\mathrm{M}_{j}}}{\partial y}+\frac{\partial w_{\mathrm{M}_{j}}}{\partial z}=0, \\
& \underbrace{\Re\left\{\overline{u_{\mathrm{M}_{2}} \frac{\partial u_{\mathrm{M}_{2}}}{\partial x}}+\overline{v_{\mathrm{M}_{2}} \frac{\partial u_{\mathrm{M}_{2}}}{\partial y}}+\overline{\left.w_{\mathrm{M}_{2}} \frac{\partial u_{\mathrm{M}_{2}}}{\partial z}\right\}}\right.}_{\mathrm{AC}}-f v_{\mathrm{M}_{j}}=-g \frac{\partial \eta_{\mathrm{M}_{j}}}{\partial x} \\
& +A_{v_{\mathrm{M}_{0}}} \frac{\partial^{2} u_{\mathrm{M}_{j}}}{\partial z^{2}}+\underbrace{g \beta z \frac{\partial S_{\mathrm{M}_{0}}}{\partial x}}_{\mathrm{GC}}+\underbrace{A_{v_{\mathrm{M}_{2}} \frac{\partial^{2} u_{\mathrm{M}_{2}}}{\partial z^{2}}}^{\partial z^{2}}}_{\mathrm{ESCO}}, \\
& \underbrace{\Re\left\{\overline{u_{\mathrm{M}_{2}} \frac{\partial v_{\mathrm{M}_{2}}}{\partial x}}+\overline{v_{\mathrm{M}_{2}} \frac{\partial v_{\mathrm{M}_{2}}}{\partial y}}+\overline{\left.w_{\mathrm{M}_{2}} \frac{\partial v_{\mathrm{M}_{2}}}{\partial z}\right\}}\right.}_{\mathrm{AC}}+f u_{\mathrm{M}_{j}}
\end{aligned}
$$




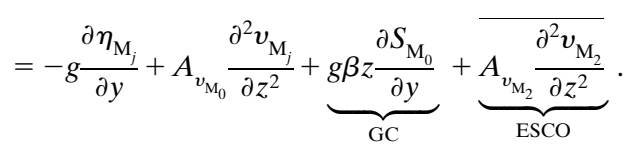

The boundary conditions are

$$
\eta_{\mathrm{M}_{j}}=a_{\mathrm{M}_{j}} \text { at } \quad x=0
$$

$[\int_{-H}^{0}\left(u_{\mathrm{M}_{j}}, v_{\mathrm{M}_{j}}\right) d z+\underbrace{\left(\left.\overline{\eta_{\mathrm{M}_{2}} u_{\mathrm{M}_{2}}}\right|_{z=0},\left.\overline{\eta_{\mathrm{M}_{2}} v_{\mathrm{M}_{2}}}\right|_{z=0}\right)}_{\text {TRFSD }}] \cdot \mathbf{n}_{h}=\underbrace{R_{i}}_{\mathrm{RD}}$

at $x=L$,

$[\int_{-H}^{0}\left(u_{\mathrm{M}_{j}}, v_{\mathrm{M}_{j}}\right) d z+\underbrace{\left(\left.\overline{\eta_{\mathrm{M}_{2}} u_{\mathrm{M}_{2}}}\right|_{z=0},\left.\overline{\eta_{\mathrm{M}_{2}} v_{\mathrm{M}_{2}}}\right|_{z=0}\right)}_{\text {TRFSD }}] \cdot \mathbf{n}_{h}=0$

at $y= \pm B / 2$,

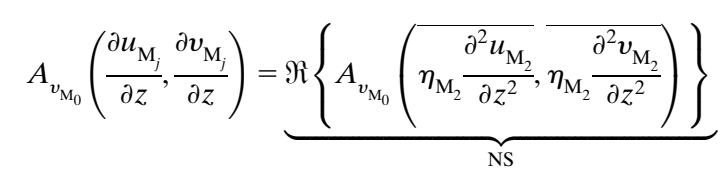

at $z=0$,

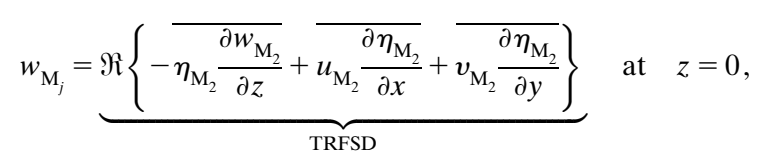

$$
\begin{aligned}
& w_{\mathrm{M}_{j}}=-u_{\mathrm{M}_{j}} \frac{\partial H}{\partial x}-v_{\mathrm{M}_{j}} \frac{\partial H}{\partial y} \quad \text { at } \quad z=-H \\
& A_{v_{\mathrm{M}_{0}}}\left(\frac{\partial u_{\mathrm{M}_{j}}}{\partial z}, \frac{\partial v_{\mathrm{M}_{j}}}{\partial z}\right)+\underbrace{\left(A_{\left.v_{\mathrm{M}_{2}} \frac{\partial u_{\mathrm{M}_{2}}}{\partial z}, A_{v_{\mathrm{M}_{2}}} \frac{\partial v_{\mathrm{M}_{2}}}{\partial z}\right)}^{\partial z}\right.}_{\text {ESCO }}=s\left(u_{\mathrm{M}_{j}}, v_{\mathrm{M}_{j}}\right) \\
& \text { at } z=-H \text {. }
\end{aligned}
$$

Here $j=0,4$, and the underbrace denotes various mechanisms that force the residual flow. Equations (B1)-(B4) show that the residual flow is forced by advective contributions of the leading order $\mathrm{M}_{2}$ tide (tidal rectification, denoted by $\mathrm{AD}$ ), density driven gravitational circulation (GC), the stress-free surface condition (NS), river discharge (RD), a return flow (TRFSD), and ESCO circulation. Since the first-order water motion equations (B1) and (B4) are linear, the residual flow components due to these forcing mechanisms can be solved separately. Hence, the solution of the residual water motion can be written as

$$
\chi_{\mathrm{M}_{j}}=\chi_{\mathrm{M}_{j}}^{\mathrm{RD}}+\chi_{\mathrm{M}_{j}}^{\mathrm{TRFS}}+\chi_{\mathrm{M}_{j}}^{\mathrm{AC}}+\chi_{\mathrm{M}_{j}}^{\mathrm{GC}}+\chi_{\mathrm{M}_{j}}^{\mathrm{NS}}+\chi_{\mathrm{M}_{j}}^{\mathrm{ESCO}}
$$

with the solution vector $\chi_{\mathrm{M}_{j}}=\left(\eta_{\mathrm{M}_{j}}, u_{\mathrm{M}_{j}}, v_{\mathrm{M}_{j}}, w_{\mathrm{M}_{j}}\right)$. All residual contributions can be calculated explicitly without information about the salinity field following Kumar et al. (2017), except ESCO and gravitational circulation, which depend on the other flow components and salinity. Note here $\chi_{\mathrm{M}_{4}}^{\mathrm{GC}}=0$, because there is no $\mathrm{M}_{4}$ forcing for the gravitational circulation.

\section{APPENDIX C}

\section{Leading-Order Salinity}

Following Wei et al. (2017), the leading-order salinity equation is given by

$$
\frac{\partial S_{\mathrm{M}_{0}}}{\partial t}=\frac{\partial}{\partial z}\left(K_{v_{\mathrm{M}_{0}}} \frac{\partial S_{\mathrm{M}_{0}}}{\partial z}\right)
$$

Since there is no horizontal salt transport at this order, the boundary conditions at the closed and landward boundaries are automatically satisfied. The remaining boundary conditions are

$$
\begin{gathered}
S_{\mathrm{M}_{0}}=S_{m} \quad \text { at } x=0, \\
K_{v_{\mathrm{M}_{0}}} \frac{\partial S_{\mathrm{M}_{0}}}{\partial z}=0 \quad \text { at } z=-H \text { and } z=0 .
\end{gathered}
$$

\section{APPENDIX D}

\section{First-Order Salinity}

The first-order salinity equation reads

$$
\frac{\partial S_{\mathrm{M}_{2}}}{\partial t}+u_{\mathrm{M}_{2}} \frac{\partial S_{\mathrm{M}_{0}}}{\partial x}+v_{\mathrm{M}_{2}} \frac{\partial S_{\mathrm{M}_{0}}}{\partial y}=K_{v_{\mathrm{M}_{0}}} \frac{\partial^{2} S_{\mathrm{M}_{2}}}{\partial z^{2}}+K_{v_{\mathrm{M}_{2}}} \frac{\partial^{2} S_{\mathrm{M}_{0}}}{\partial z^{2}} .
$$

As $S_{\mathrm{M}_{0}}$ is vertically homogeneous under periodically weakly stratified conditions, $\partial S_{\mathrm{M}_{0}} / \partial z=0$, the above equation reduces to

$$
\frac{\partial S_{\mathrm{M}_{2}}}{\partial t}+u_{\mathrm{M}_{2}} \frac{\partial S_{\mathrm{M}_{0}}}{\partial x}+v_{\mathrm{M}_{2}} \frac{\partial S_{\mathrm{M}_{0}}}{\partial y}=K_{v_{\mathrm{M}_{0}}} \frac{\partial^{2} S_{\mathrm{M}_{2}}}{\partial z^{2}}
$$

The boundary conditions for the first-order salinity equation are

$$
\begin{gathered}
\bar{S}_{\mathrm{M}_{2}}=0 \quad \text { at } \quad x=0, \\
\left(\int_{-H}^{0} \overline{u_{\mathrm{M}_{2}} S_{\mathrm{M}_{0}}} d z, \int_{-H}^{0} \overline{v_{\mathrm{M}_{2}} S_{\mathrm{M}_{0}}} d z\right) \cdot \mathbf{n}_{h}=0 \\
\text { at } y= \pm B / 2 \text { or } x=L, \\
K_{v_{M_{0}}} \frac{\partial S_{M_{2}}}{\partial z}=0 \text { at } z=-H, 0 .
\end{gathered}
$$

Here the overbars denote tidal average. Solving the above system of equations yields an analytical expression for $S_{\mathrm{M}_{2}}$, as found by Wei et al. (2017):

$$
\begin{aligned}
S_{\mathrm{M}_{2}}= & S_{z_{1}}\left(\frac{\partial \eta_{\mathrm{M}_{2}}}{\partial x} \frac{\partial S_{\mathrm{M}_{0}}}{\partial x}+\frac{\partial \eta_{\mathrm{M}_{2}}}{\partial y} \frac{\partial S_{\mathrm{M}_{0}}}{\partial y}\right) \\
& +S_{z_{2}}\left(\frac{\partial \eta_{\mathrm{M}_{2}}}{\partial y} \frac{\partial S_{\mathrm{M}_{0}}}{\partial x}-\frac{\partial \eta_{\mathrm{M}_{2}}}{\partial x} \frac{\partial S_{\mathrm{M}_{0}}}{\partial y}\right) .
\end{aligned}
$$



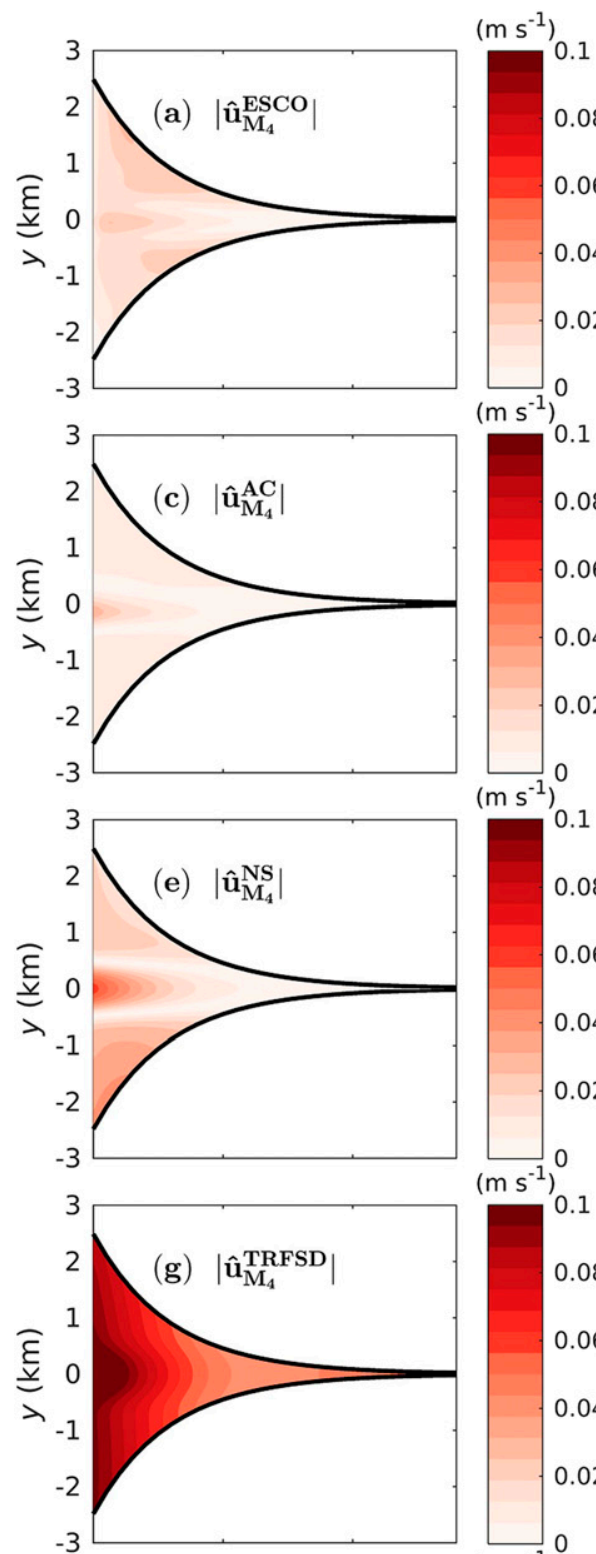

0.1
0.08
0.06
0.04
0.02
0

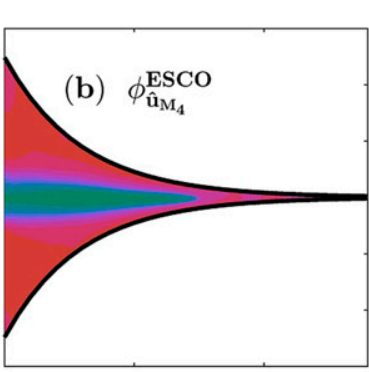

(degree) 180
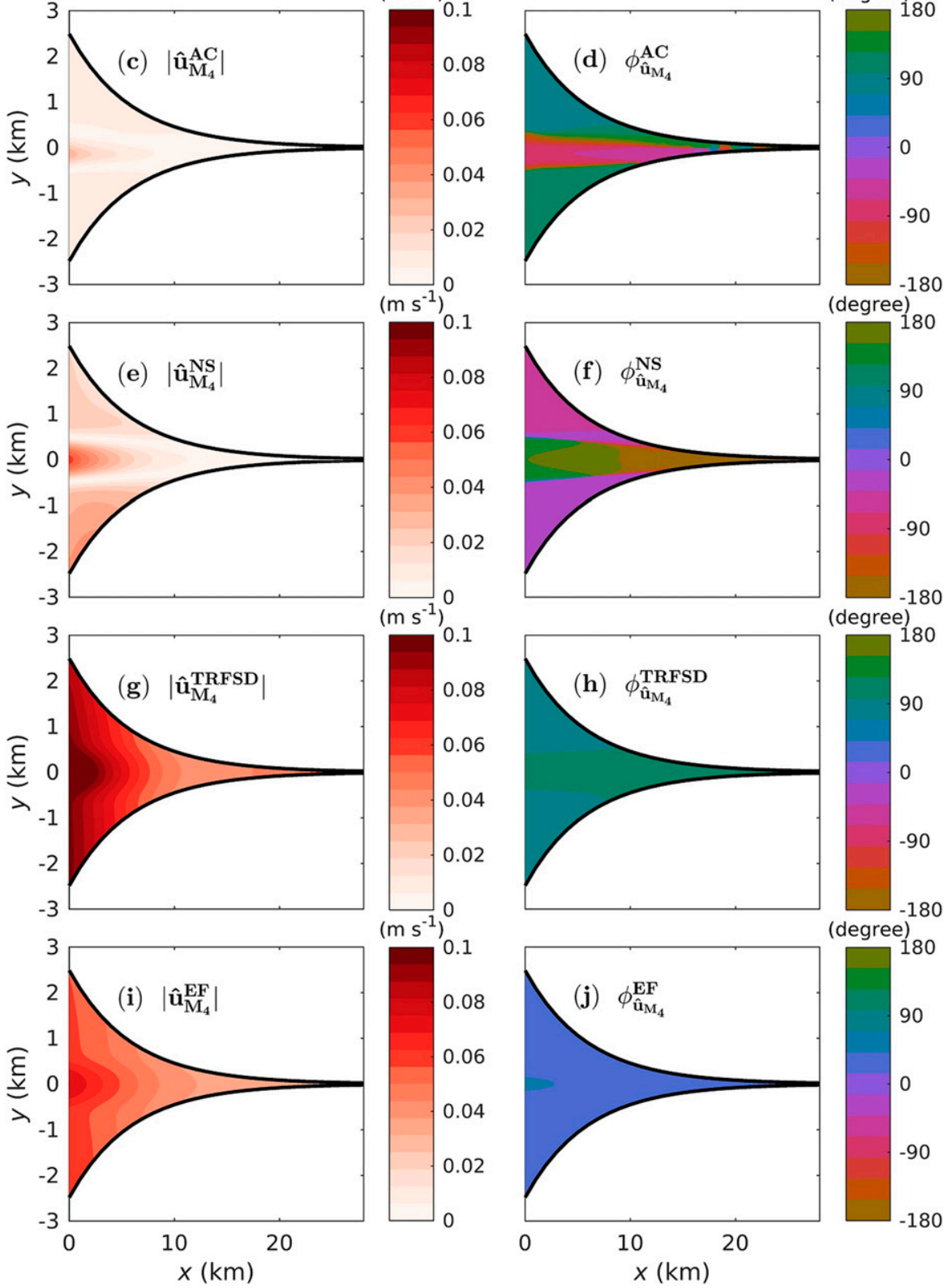

FIG. E1. (left) Amplitude and (right) phase of the depth-averaged quarter-diurnal tidal flow due to (a),(b) eddy viscosity-shear covariance (ESCO); (c),(d) advection (AC); (e),(f) shear-free surface condition (NS); (g),(h) tidal return flow that compensates Stokes drift (TRF); and (i),(j) external quarter-diurnal tidal forcing (EF). 
Here $S_{z_{1}}$ and $S_{z_{2}}$ are depth-dependent functions that describe the vertical salinity structure, given by,

$$
\begin{aligned}
S_{z_{1}}= & \frac{b_{1} \gamma_{1}\left(\cosh \alpha_{1} z-\frac{\alpha_{1} \sinh \alpha_{1} H}{\beta \sinh \beta H} \cosh \beta z\right)}{K_{v}\left(\alpha_{1}^{2}-\beta^{2}\right)}+ \\
& \left.\frac{b_{2} \gamma_{2}\left(\cosh \alpha_{2} z-\frac{\alpha_{2} \sinh \alpha_{2} H}{\beta \sinh \beta H} \cosh \beta z\right)}{K_{v}\left(\alpha_{2}^{2}-\beta^{2}\right)}+\frac{b_{1}+b_{2}}{i \sigma}, \quad \text { D } 5\right) \\
S_{z_{2}}= & \frac{i b_{1} \gamma_{1}\left(\cosh \alpha_{1} z-\frac{\alpha_{1} \sinh \alpha_{1} H}{\beta \sinh \beta H} \cosh \beta z\right)}{K_{v}\left(\alpha_{1}^{2}-\beta^{2}\right)} \\
& +\frac{i b_{2} \gamma_{2}\left(\frac{\alpha_{2} \sinh \alpha_{2} H}{\beta \sinh \beta H} \cosh \beta z-\cosh \alpha_{2} z\right)}{K_{v}\left(\alpha_{2}^{2}-\beta^{2}\right)}+\frac{b_{1}-b_{2}}{\sigma}
\end{aligned}
$$

By taking the vertical derivative of $S_{z_{1}}$, and $S_{z_{2}}$, the vertical structure of stratification can be derived,

$$
\begin{aligned}
& S_{z z_{1}}= \frac{b_{1} \gamma_{1}\left(\alpha_{1} \sinh \alpha_{1} z-\frac{\alpha_{1} \sinh \alpha_{1} H}{\sinh \beta H} \sinh \beta z\right)}{K_{v}\left(\alpha_{1}^{2}-\beta^{2}\right)} \\
&+\frac{b_{2} \gamma_{2}\left(\alpha_{2} \sinh \alpha_{2} z-\frac{\alpha_{2} \sinh \alpha_{2} H}{\sinh \beta H} \sinh \beta z\right)}{K_{v}\left(\alpha_{2}^{2}-\beta^{2}\right)}, \\
& S_{z z_{2}}= \frac{i b_{1} \gamma_{1}\left(\alpha_{1} \sinh \alpha_{1} z-\frac{\alpha_{1} \sinh \alpha_{1} H}{\sinh \beta H} \sinh \beta z\right)}{K_{v}\left(\alpha_{1}^{2}-\beta^{2}\right)} \\
&+\frac{i b_{2} \gamma_{2}\left(\frac{\alpha_{2} \sinh \alpha_{2} H}{\beta \sinh \beta H} \cosh \beta z-\alpha_{2} \sinh \alpha_{2} z\right)}{K_{v}\left(\alpha_{2}^{2}-\beta^{2}\right)} \\
& \text { with } \quad \alpha_{1}=\sqrt{i(\sigma+f) / A_{v}}, \alpha_{2}=\sqrt{i(\sigma-f) / A_{v}}, \\
& \beta=\sqrt{i \sigma / K_{v}}, b_{j}=g / 2 \alpha_{j}^{2} A_{v}, \\
& \gamma_{j}=s /\left(\alpha_{j} A_{v} \sinh \alpha_{j} H+s \cosh \alpha_{j} H\right), j=1,2 .
\end{aligned}
$$

\section{APPENDIX E}

\section{Tidal Water Motion}

The semidiurnal $\left(\mathrm{M}_{2}\right)$ tidal surface amplitude is almost uniform in the estuary, slightly increasing from $1.95 \mathrm{~m}$ at the estuarine mouth to $2.05 \mathrm{~m}$ at the head of the estuary (Fig. 11a). The phase relative to that at the mouth is less than $5^{\circ}$ everywhere, indicating $\eta_{\mathrm{M}_{2}}$ changes almost without delay throughout the short estuary (Fig. 11b). Meanwhile, the amplitude of the depth-averaged semidiurnal tidal velocity $u_{\mathrm{M}_{2}}$ monotonically decreases landward (Fig. 11c); and its phase $\left(\phi_{\mathrm{M}_{2}}\right.$, the phase difference between the depth-averaged $u_{\mathrm{M}_{2}}$ and $\eta_{\mathrm{M}_{2}}$ at the mouth) is close to $90^{\circ}$ throughout the estuary (Fig. 11d). The above features confirm the semidiurnal tide in the idealized estuary is almost a standing wave.
The amplitude of the depth-mean along-channel quarterdiurnal $\left(\mathrm{M}_{4}\right)$ tidal velocities, $\left|u_{\mathrm{M}_{4}}\right|$, is about one-third of that of the quarter-diurnal tidal velocities (Fig. 11e). The quarterdiurnal tidal currents can strongly influence the flow asymmetry, according to Friedrichs and Aubrey (1988). To measure this influence, the relative phase $(\Delta \phi)$ between the semidiurnal and quarter-diurnal tidal velocities,

$$
\Delta \phi=2 \phi_{\mathrm{M}_{2}}-\phi_{\mathrm{M}_{4}}
$$

is calculated. Figure 11f shows that, the quarter-diurnal tidal currents promote ebb dominance in the channel $\left(90^{\circ}<\Delta \phi<\right.$ $\left.270^{\circ}\right)$ and flood dominance on the shoals $\left(0^{\circ}<\Delta \phi<90^{\circ}\right)$. A cross-sectional view of $\left|u_{\mathrm{M}_{4}}\right|$ and $\Delta \phi$ (at $x=10 \mathrm{~km}$ ) shows that $u_{\mathrm{M}_{4}}$ tend to promote flood dominance near the bottom and ebb dominance in the upper layers where the quarter-diurnal tidal currents are strongest. The quarter-diurnal tidal currents are decomposed into different components due to different processes. As shown in Fig. E1, along-channel quarter-diurnal tidal velocities are dominated by TRFSD and EF, followed by $\mathrm{NS}$, whereas that induced by ESCO is minor.

\section{REFERENCES}

Basdurak, N. B., K. Huguenard, A. Valle-Levinson, M. Li, and R. Chant, 2017: Parameterization of mixing by secondary circulation in estuaries. J. Geophys. Res. Oceans, 122, 56665688, https://doi.org/10.1002/2016JC012328.

_ A. Valle-Levinson, and P. Cheng, 2013: Lateral structure of tidal asymmetry in vertical mixing and its impact on exchange flow in a coastal plain estuary. Cont. Shelf Res., 64, 20-32, https://doi.org/10.1016/j.csr.2013.05.005.

Bolaños, R., J. M. Brown, L. O. Amoudry, and A. J. Souza, 2013: Tidal, riverine, and wind influences on the circulation of a macrotidal estuary. J. Phys. Oceanogr., 43, 29-50, https:// doi.org/10.1175/JPO-D-11-0156.1.

Burchard, H., and R. D. Hetland, 2010: Quantifying the contributions of tidal straining and gravitational circulation to residual circulation in periodically stratified tidal estuaries. J. Phys. Oceanogr., 40, 1243-1262, https://doi.org/10.1175/ 2010JPO4270.1.

_ , and H. M. Schuttelaars, 2012: Analysis of tidal straining as driver for estuarine circulation in well-mixed estuaries. J. Phys. Oceanogr., 42, 261-271, https://doi.org/10.1175/JPOD-11-0110.1.

— , R. D. Hetland, E. Schulz, and H. M. Schuttelaars, 2011: Drivers of residual estuarine circulation in tidally energetic estuaries: Straight and irrotational channels with parabolic cross section. J. Phys. Oceanogr., 41, 548-570, https://doi.org/ 10.1175/2010JPO4453.1.

Cheng, P., A. Valle-Levinson, and H. E. De Swart, 2010: Residual currents induced by asymmetric tidal mixing in weakly stratified narrow estuaries. J. Phys. Oceanogr., 40, 2135-2147, https://doi.org/10.1175/2010JPO4314.1.

Davies, A. M., S. C. Kwong, and R. A. Flather, 1997: Formulation of a variable-function three-dimensional model, with applications to the $\mathrm{M}_{2}$ and $\mathrm{M}_{4}$ tide on the North-west European Continental Shelf. Cont. Shelf Res., 17, 165-204, https:// doi.org/10.1016/S0278-4343(96)00025-8.

Dijkstra, Y. M., H. M. Schuttelaars, and H. Burchard, 2017: Generation of exchange flows in estuaries by tidal and gravitational eddy viscosity-shear covariance (ESCO). 
J. Geophys. Res. Oceans, 122, 4217-4237, https://doi.org/ 10.1002/2016JC012379.

Dronkers, J., 1986: Tidal asymmetry and estuarine morphology. Neth. J. Sea Res., 20, 117-131, https://doi.org/10.1016/00777579(86)90036-0.

Fox, C., R. Harrop, and A. Wimpenny, 1999: Feeding ecology of herring (Clupea harengus) larvae in the turbid Blackwater Estuary. Mar. Biol., 134, 353-365, https://doi.org/10.1007/ s002270050552.

Friedrichs, C. T., and D. G. Aubrey, 1988: Non-linear tidal distortion in shallow well-mixed estuaries: A synthesis. Estuarine Coastal Shelf Sci., 27, 521-545, https://doi.org/10.1016/02727714(88)90082-0.

- , and -1994 : Tidal propagation in strongly convergent channels. J. Geophys. Res., 99, 3321-3336, https://doi.org/ 10.1029/93JC03219.

Geyer, W. R., 1995: Tide-induced mixing in the Amazon frontal zone.J. Geophys. Res., 100, 2341-2353, https://doi.org/10.1029/ 94JC02543.

— , and J. D. Smith, 1987: Shear instability in a highly stratified estuary. J. Phys. Oceanogr., 17, 1668-1679, https://doi.org/ 10.1175/1520-0485(1987)017<1668:SIIAHS > 2.0.CO;2.

— J. J. Trowbridge, and M. M. Bowen, 2000: The dynamics of a partially mixed estuary. J. Phys. Oceanogr., 30, 20352048, https://doi.org/10.1175/1520-0485(2000)030<2035: TDOAPM $>2.0 . \mathrm{CO} ; 2$.

- D. K. Ralston, and J.-L. Chen, 2020: Mechanisms of exchange flow in an estuary with a narrow, deep channel and wide, shallow shoals. J. Geophys. Res. Oceans, 125, e2020JC016092, https://doi.org/10.1029/2020JC016092.

Holleman, R., W. Geyer, and D. Ralston, 2016: Stratified turbulence and mixing efficiency in a salt wedge estuary. J. Phys. Oceanogr., 46, 1769-1783, https://doi.org/10.1175/JPO-D-150193.1.

Huguenard, K., A. Valle-Levinson, M. Li, R. Chant, and A. Souza, 2015: Linkage between lateral circulation and near-surface vertical mixing in a coastal plain estuary. J. Geophys. Res. Oceans, 120, 4048-4067, https://doi.org/ 10.1002/2014JC010679.

Huijts, K., H. Schuttelaars, H. De Swart, and C. Friedrichs, 2009: Analytical study of the transverse distribution of along-channel and transverse residual flows in tidal estuaries. Cont. Shelf Res., 29, 89-100, https://doi.org/10.1016/j.csr.2007.09.007.

Jay, D. A., 1991: Green's law revisited: Tidal long-wave propagation in channels with strong topography. J. Geophys. Res., 96, 20 585-20 598, https://doi.org/10.1029/91JC01633.

—_, and J. D. Musiak, 1994: Particle trapping in estuarine tidal flows. J. Geophys. Res., 99, 20 445-20 461, https://doi.org/ 10.1029/94JC00971.

Kasai, A., A. E. Hill, T. Fujiwara, and J. H. Simpson, 2000: Effect of the Earth's rotation on the circulation in regions of freshwater influence. J. Geophys. Res., 105, 16 961-16 969, https://doi.org/ 10.1029/2000JC900058.

Kumar, M., H. M. Schuttelaars, P. C. Roos, and M. Möller, 2016: Three-dimensional semi-idealized model for tidal motion in tidal estuaries. Ocean Dyn., 66, 99-118, https://doi.org/ 10.1007/s10236-015-0903-1.

_, , and —, 2017: Three-dimensional semi-idealized model for estuarine turbidity maxima in tidally dominated estuaries. Ocean Modell., 113, 1-21, https://doi.org/10.1016/ j.ocemod.2017.03.005.

Lerczak, J. A., and R. W. Geyer, 2004: Modeling the lateral circulation in straight, stratified estuaries. J. Phys. Oceanogr., 34,
1410-1428, https://doi.org/10.1175/1520-0485(2004)034<1410: MTLCIS $>2.0 . C O ; 2$.

Lewis, R. E., and R. J. Uncles, 2003: Factors affecting longitudinal dispersion in estuaries of different scale. Ocean Dyn., 53, 197207, https://doi.org/10.1007/s10236-003-0030-2.

Li, C., A. Valle-Levinson, L. P. Atkinson, K. C. Wong, and K. M. Lwiza, 2004: Estimation of drag coefficient in James River estuary using tidal velocity data from a vessel-towed ADCP. J. Geophys. Res., 109, C03034, https://doi.org/10.1029/2003JC001991.

Li, M., and L. Zhong, 2009: Flood-ebb and spring-neap variations of mixing, stratification and circulation in Chesapeake Bay. Cont. Shelf Res., 29, 4-14, https://doi.org/10.1016/ j.csr.2007.06.012.

Lorentz, H. A., 1926: Verslag staatscommissie Zuiderzee 19181926. Algemeene Landsdrukkerij, 345 pp.

Pacanowski, R., and S. Philander, 1981: Parameterization of vertical mixing in numerical models of tropical oceans. J. Phys. Oceanogr., 11, 1443-1451, https://doi.org/10.1175/1520-0485(1981) 011<1443:POVMIN>2.0.CO;2.

Peters, H., 1997: Observations of stratified turbulent mixing in an estuary: Neap-to-spring variations during high river flow. Estuarine Coastal Shelf Sci., 45, 69-88, https://doi.org/10.1006/ ecss.1996.0180.

- 1999: Spatial and temporal variability of turbulent mixing in an estuary. J. Mar. Res., 57, 805-845, https://doi.org/10.1357/ 002224099321514060.

Prandle, D., 2004: Saline intrusion in partially mixed estuaries. Estuarine Coastal Shelf Sci., 59, 385-397, https://doi.org/ 10.1016/j.ecss.2003.10.001.

Ridderinkhof, W., H. De Swart, M. Van Der Vegt, N. Alebregtse, and P. Hoekstra, 2014: Geometry of tidal inlet systems: A key factor for the net sediment transport in tidal inlets. J. Geophys. Res. Oceans, 119, 6988-7006, https://doi.org/10.1002/2014JC010226.

Rippeth, T. P., N. R. Fisher, and J. H. Simpson, 2001: The cycle of turbulent dissipation in the presence of tidal straining. J. Phys. Oceanogr., 31, 2458-2471, https://doi.org/10.1175/1520-0485(2001) 031<2458:TCOTDI $>2.0 . \mathrm{CO} ;$.

Rohr, J., E. Itsweire, K. Helland, and C. Van Atta, 1988: Growth and decay of turbulence in a stably stratified shear flow. J. Fluid Mech., 195, 77-111, https://doi.org/10.1017/S0022112088002332.

Ross, L., K. Huguenard, and A. Sottolichio, 2019: Intratidal and fortnightly variability of vertical mixing in a macrotidal estuary: The Gironde. J. Geophys. Res. Oceans, 124, 2641-2659, https://doi.org/10.1029/2018JC014456.

Savenije, H. H., 2015: Prediction in ungauged estuaries: An integrated theory. Water Resour. Res., 51, 2464-2476, https:// doi.org/10.1002/2015WR016936.

Schettini, C. A., A. Valle-Levinson, and E. C. Truccolo, 2017: Circulation and transport in short, low-inflow estuaries under anthropogenic stresses. Reg. Stud. Mar. Sci., 10, 52-64, https:// doi.org/10.1016/j.rsma.2017.01.004.

Scully, M. E., and C. T. Friedrichs, 2003: The influence of asymmetries in overlying stratification on near-bed turbulence and sediment suspension in a partially mixed estuary. Ocean Dyn., 53, 208-219, https://doi.org/10.1007/s10236-003-0034-y.

- , and 2007: The importance of tidal and lateral asymmetries in stratification to residual circulation in partially mixed estuaries. J. Phys. Oceanogr., 37, 1496-1511, https:// doi.org/10.1175/JPO3071.1.

, and W. R. Geyer, 2012: The role of advection, straining, and mixing on the tidal variability of estuarine stratification. J. Phys. Oceanogr., 42, 855-868, https://doi.org/10.1175/ JPO-D-10-05010.1. 
Simons, R. D., S. G. Monismith, F. J. Saucier, L. E. Johnson, and G. Winkler, 2010: Modelling stratification and baroclinic flow in the estuarine transition zone of the St. Lawrence estuary. Atmos.-Ocean, 48, 132-146, https://doi.org/10.3137/ OC316.2010.

Simpson, J. H., J. Brown, J. Matthews, and G. Allen, 1990: Tidal straining, density currents, and stirring in the control of estuarine stratification. Estuaries, 13, 125-132, https://doi.org/ $10.2307 / 1351581$.

—, H. Burchard, N. R. Fisher, and T. P. Rippeth, 2002: The semidiurnal cycle of dissipation in a ROFI: Model-measurement comparisons. Cont. Shelf Res., 22, 1615-1628, https://doi.org/ 10.1016/S0278-4343(02)00025-0.

—, E. Williams, L. Brasseur, and J. Brubaker, 2005: The impact of tidal straining on the cycle of turbulence in a partially stratified estuary. Cont. Shelf Res., 25, 51-64, https://doi.org/ 10.1016/j.csr.2004.08.003.

Stacey, M. T., and D. K. Ralston, 2005: The scaling and structure of the estuarine bottom boundary layer. J. Phys. Oceanogr., 35, 55-71, https://doi.org/10.1175/JPO-2672.1.

—, S. G. Monismith, and J. R. Burau, 1999: Observations of turbulence in a partially stratified estuary. J. Phys. Oceanogr., 29, 1950-1970, https://doi.org/10.1175/1520-0485(1999)029<1950: OOTIAP $>2.0 . C O ; 2$.

— J. R. Burau, and S. G. Monismith, 2001: Creation of residual flows in a partially stratified estuary. J. Geophys. Res., 106, 17 013-17 037, https://doi.org/10.1029/2000JC000576.

_ density stratification in the creation of estuarine subtidal circulation. J. Geophys. Res., 113, C08016, https://doi.org/ 10.1029/2007JC004581.
Talbot, J. W., 1967: Hydrography of the estuary of the River Blackwater. Fish. Invest., 25, 92 pp.

Townsend, A., 1961: Equilibrium layers and wall turbulence. J. Fluid Mech., 11, 97-120, https://doi.org/10.1017/S0022112061000883.

Uijttewaal, W., and R. Booij, 2000: Effects of shallowness on the development of free-surface mixing layers. Phys. Fluids, 12, 392-402, https://doi.org/10.1063/1.870317.

Valle-Levinson, A., C. Reyes, and R. Sanay, 2003: Effects of bathymetry, friction, and rotation on estuary-ocean exchange. J. Phys. Oceanogr., 33, 2375-2393, https://doi.org/10.1175/ 1520-0485(2003)033<2375:EOBFAR > 2.0.CO;2.

Wei, X., G. P. Schramkowski, and H. M. Schuttelaars, 2016: Salt dynamics in well-mixed estuaries: Importance of advection by tides. J. Phys. Oceanogr., 46, 1457-1475, https://doi.org/10.1175/ JPO-D-15-0045.1.

—, M. Kumar, and H. M. Schuttelaars, 2017: Three-dimensional salt dynamics in well-mixed estuaries: Influence of estuarine convergence, Coriolis, and bathymetry. J. Phys. Oceanogr., 47, 1843-1871, https://doi.org/10.1175/JPO-D-16-0247.1.

,-- , and,- 2018 : Three-dimensional sediment dynamics in well-mixed estuaries: Importance of the internally generated overtide, spatial settling lag, and gravitational circulation. J. Geophys. Res. Oceans, 123, 1062-1090, https:// doi.org/10.1002/2017JC012857.

West, J., and K. Shiono, 1988: Vertical turbulent mixing processes on ebb tides in partially mixed estuaries. Estuarine Coastal Shelf Sci., 26, 51-66, https://doi.org/10.1016/0272-7714(88)90011-X.

Zitman, T. J., and H. M. Schuttelaars, 2012: Importance of crosschannel bathymetry and eddy viscosity parameterisation in modelling estuarine flow. Ocean Dyn., 62, 603-631, https:// doi.org/10.1007/s10236-011-0513-5. 